\title{
تقييم المبادرة المجتمعية "نحو تعلم أفضل" بمحافظة أسوان (دراسة حالة)
}

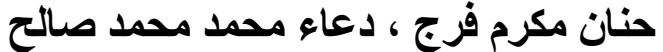 \\ معهد بحوث الإششاد الزراعي والتنمية الريفيةـ قسم بحوث المجتمع الريفي
}

Received: May. 1, 2018

Accepted: Jun. $\bullet, 2018$

\begin{abstract}
المستخلص

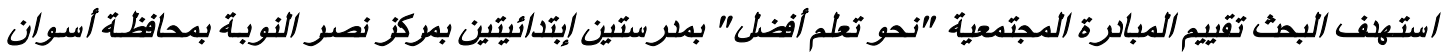

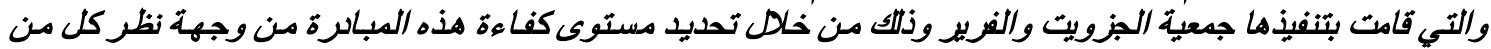

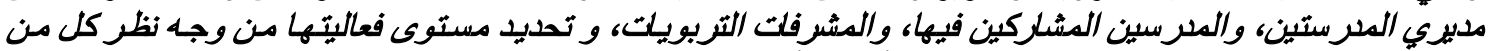

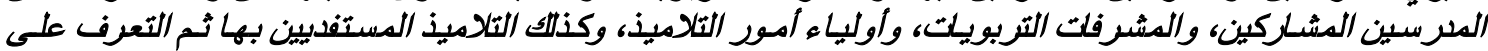

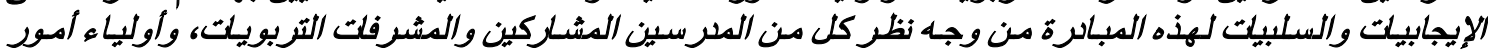

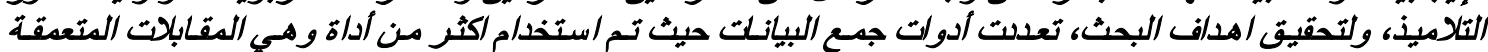

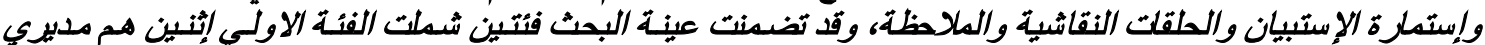

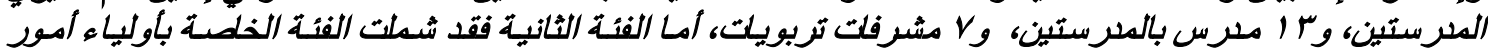

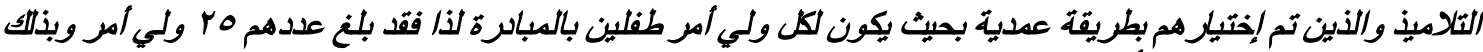

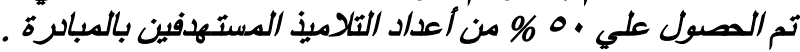

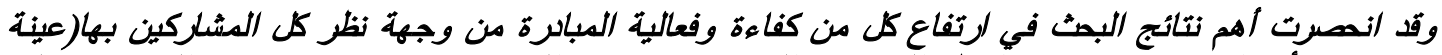

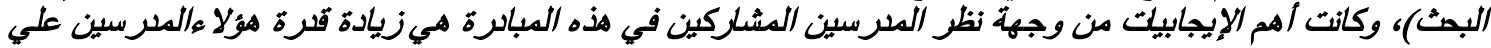

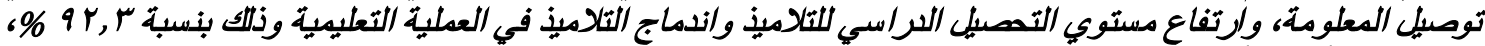

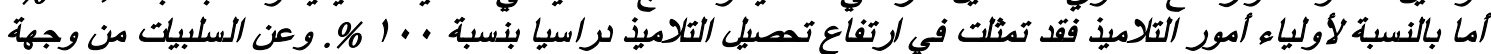

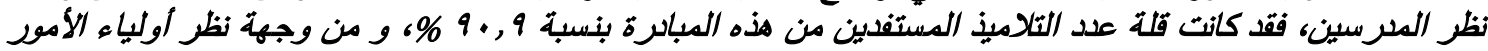

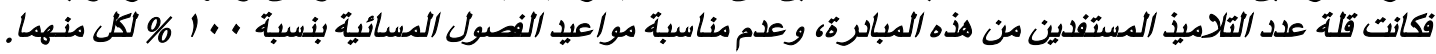

الكلمت الاسترشادية: كفاءة وفعالية المبارة

ومن ثم فإن الحديث عن التنمية بمفاهيمها المختلفة أمئة

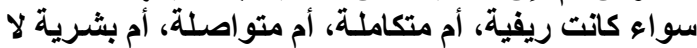

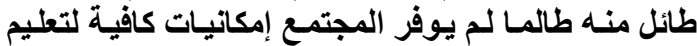

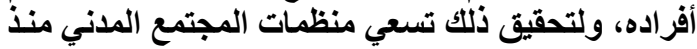
إنشائها القيام بوظائف ومهام تعبر عن إحتياجـات حقيقية التئية

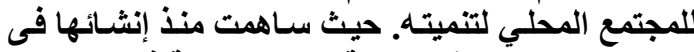

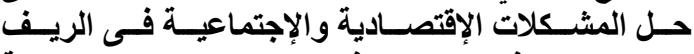

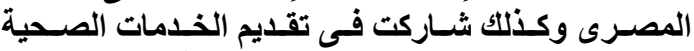

والتعليمية وخدمات الرعاية الإجتماعية للأسر الفقيرة.

وقد أكدا المؤتمر الدولى للسكان والتنميـة ( 9 و 9 1) على أن منظمات المجتمع المدني قد دلديكت المعت التنمية عموما

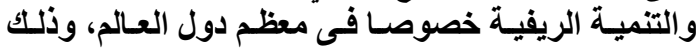

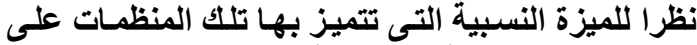

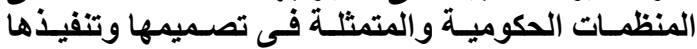

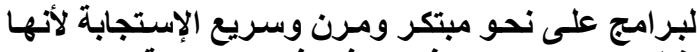

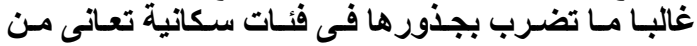

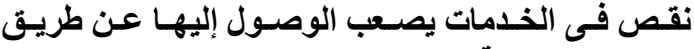
القتوات الحكومية. .
المقدمة والمشكلة البحثية: تعتبر عملية التربية والتعليم من أهم العوامل المئمة المؤثرة

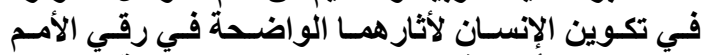

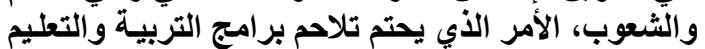

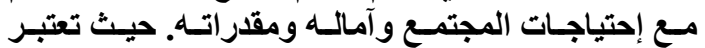

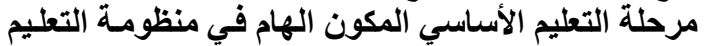

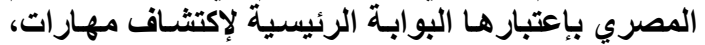

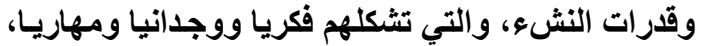

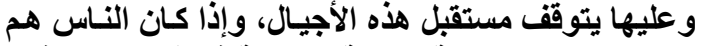

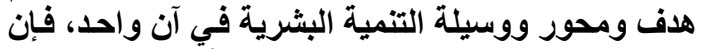

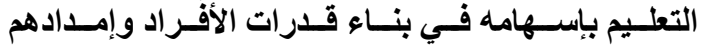

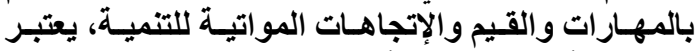

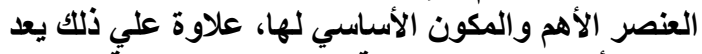

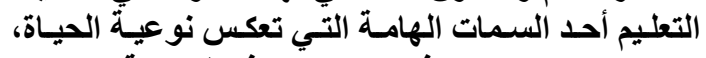

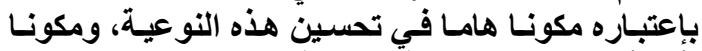

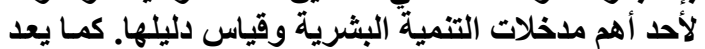

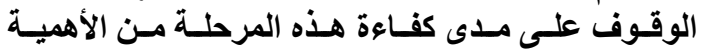

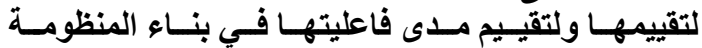
التعليمية المتكاملة كما يعتبر هدفا محوريا في العديد من فئن الاراسات الأكاديمية خاصة المنهجية والتقيمية. 
وبالتالي تحقيق التنمية المنشودة فيه وعليه فقد تبلورت الإنه مشكله آلبحث في الإجابه على التساؤلات الآتية

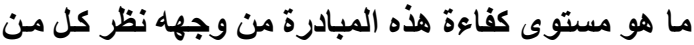

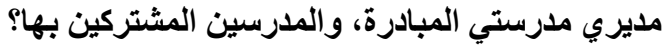

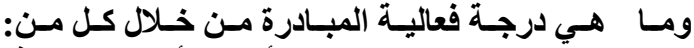

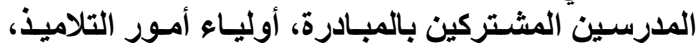

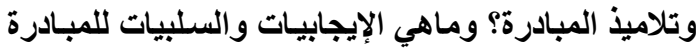

من وجه نظر كل من المدرسين وأولياء الأمور ؟ الأبيات

أهداف البحث

في إطار مشكله البحث فقد تحددت أهدافها فيما يلي:

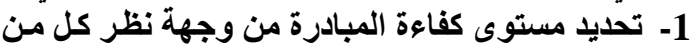

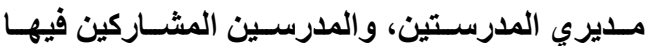
والمشرفات التربويات.

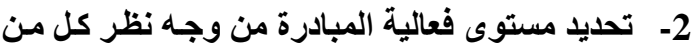

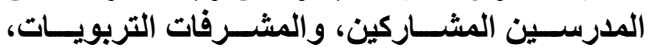

وأولياء أمور التلاميذ، والتلاميذ المستفيدين والمين منها.

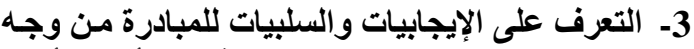
نظر كل من المدرسين المشاركين فيها، وأولياء أمور التلاميذ .

$$
\text { الإطار النظري : }
$$

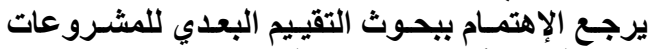

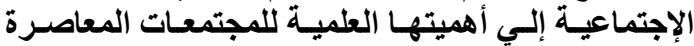

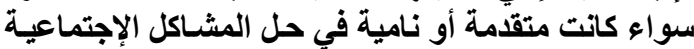

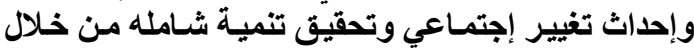

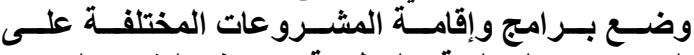

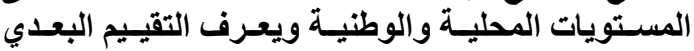

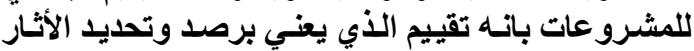

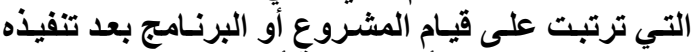

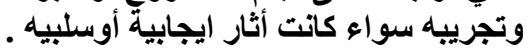

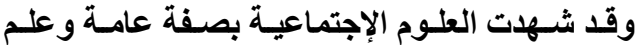

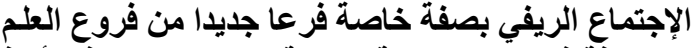

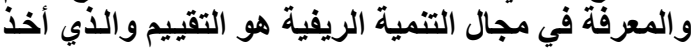

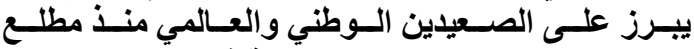

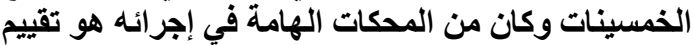
الكفاعة و الفعالية (بركات ، r . . . Y).

ويعتبر مفهـوم الكفــاعة والفعاليـة مـن أكثر المفـاهيم

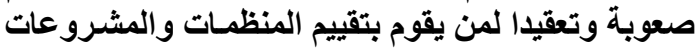

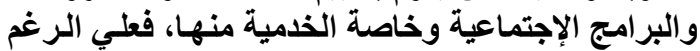

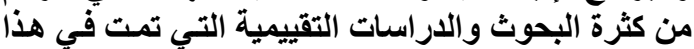

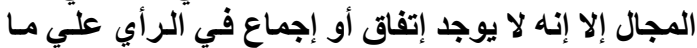

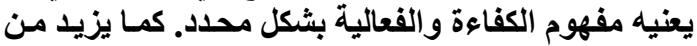

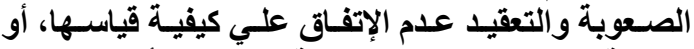

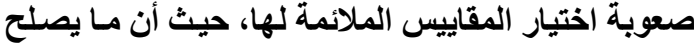

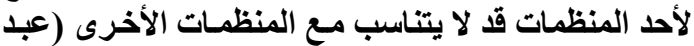

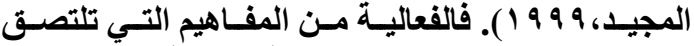

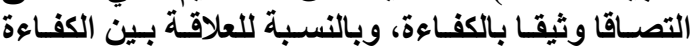

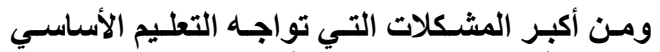

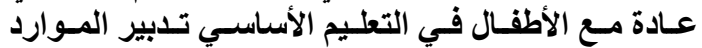

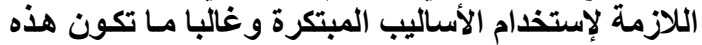

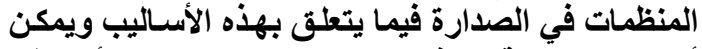

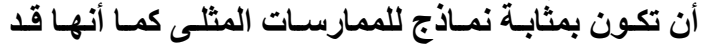

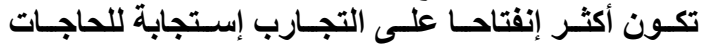

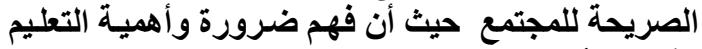

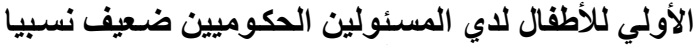

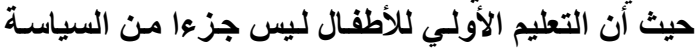

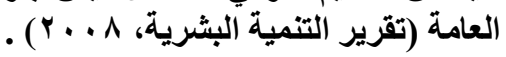

وبـالر غم من إتبـاع مصر في السنوات الأخيرة عدة

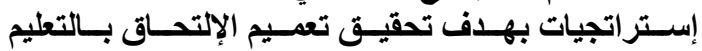

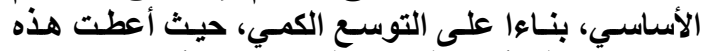

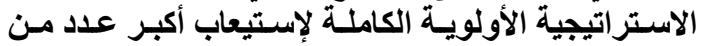

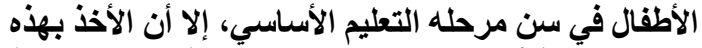

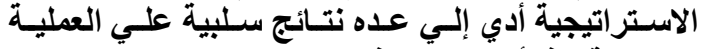

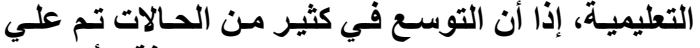

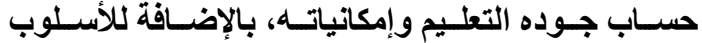

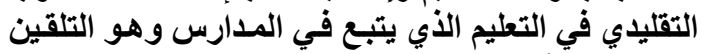

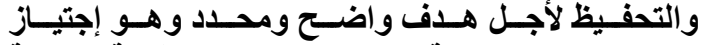

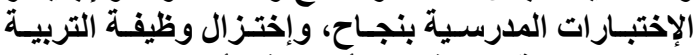

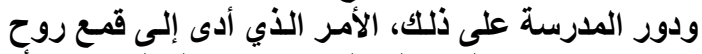

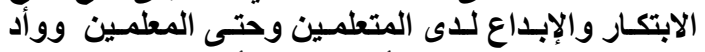

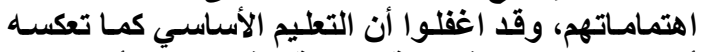

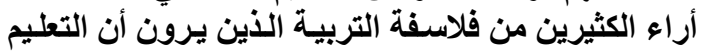

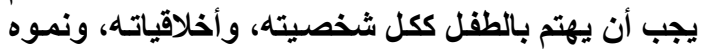

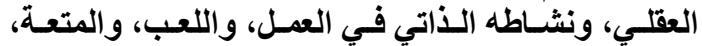
والنمو الطبيعي.

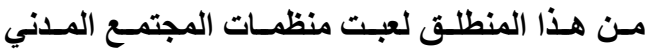

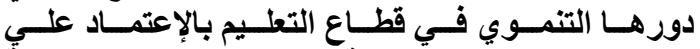

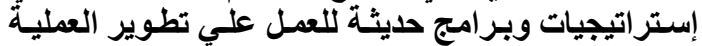

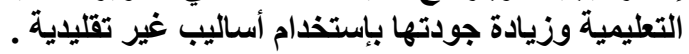

وعلى ذلك فإن مجال التربية والتعليم في أمس الحاجة

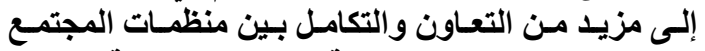

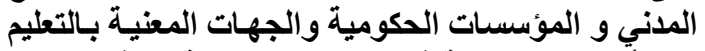

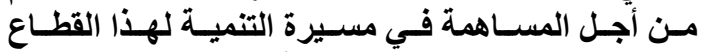

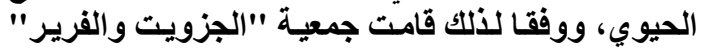

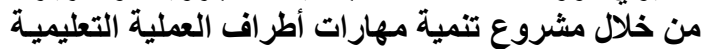

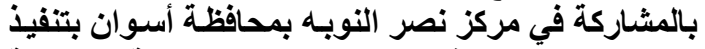

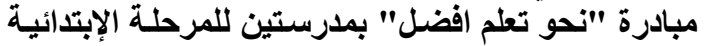

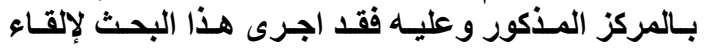

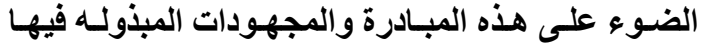

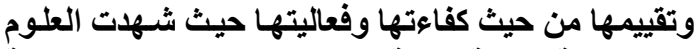

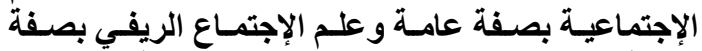

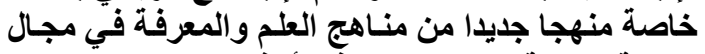

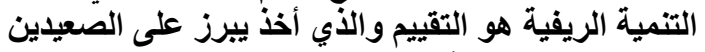

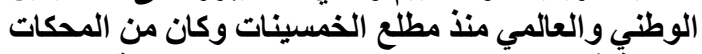

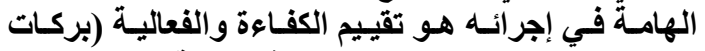

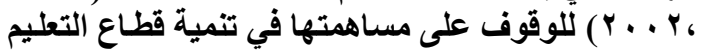


ويثير "جيمس برايس" نقلا عن "بو رقبة" إلى أن إن

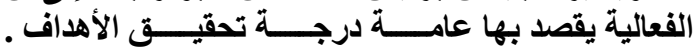

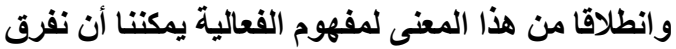

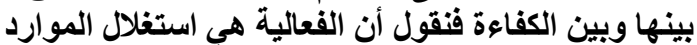

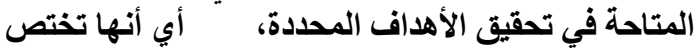

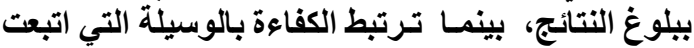

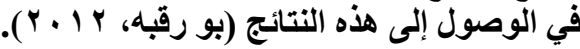

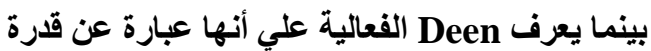

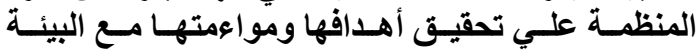

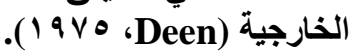

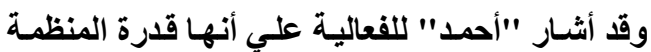

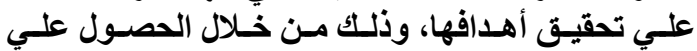

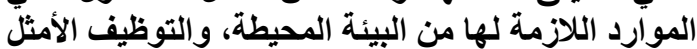

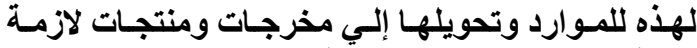

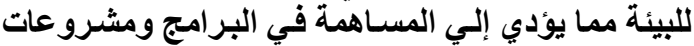

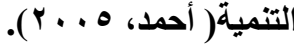

ومما سبق عرضـه من مفـاهيم للفعالية يمكن القول

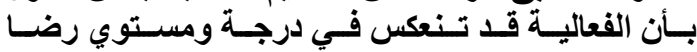

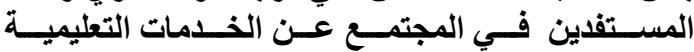
و التريوية، واستجابة أفراد المجتمع للتعاون والمشــاركة

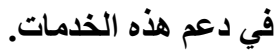

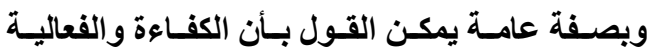

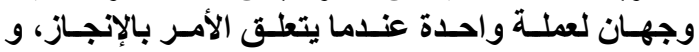
يصب الفصل بينهما واقعيا ذلكك لأن كلاهمـا يقود للآخر

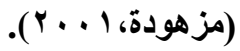

وفي هذا البحث تم التركيز على تقييم أحد المبادرات

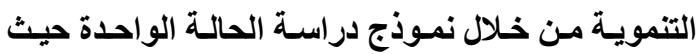

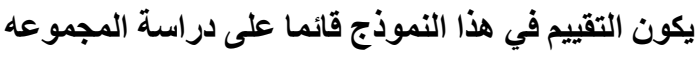
التي عنيت بمشروع معين لمعرفة مدى تأثر ها سلبا أو إيجابا بالمشروع، وتقتصر الدراسة على حقبة مابعد تنفيذ

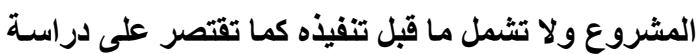

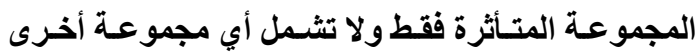

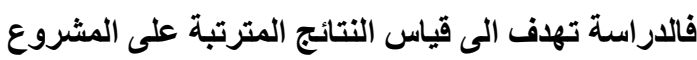
أو البرنـامج في أعقاب المشـاركة الفعلية للمبحوثين في

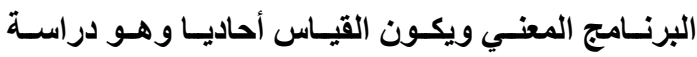
المجموعة المتأثرة في فترة ما بعد تنفيذ المشروع أو الو مـا يثـار اليـه دراسـة بعديـة فقط لا تتضـمن البعدي القبلـي

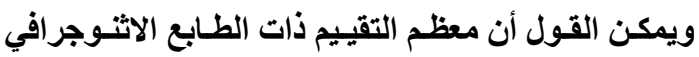

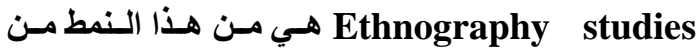

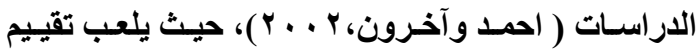
أنثطة المؤسسات التطوعية دوراً فى غاية الأهمية سواء الهاء

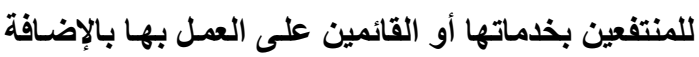

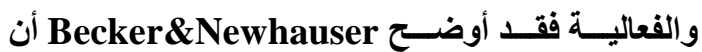

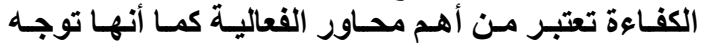
المنظمة نحو تحقيق أهدافها (19v0، Becker (1 ).

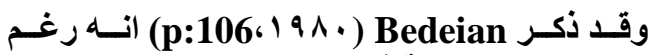

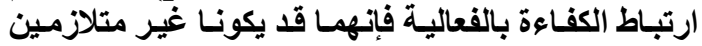

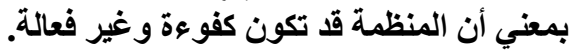

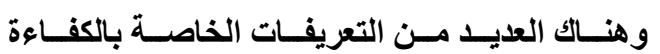

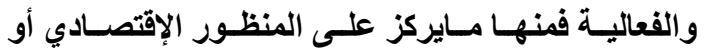

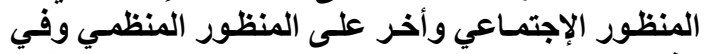
هذا البحث سوف نركز على بعض الإنى التعريفات من المنظور الإجتماعي والمنظمي .

وقد عرف "سويلم" الكفاءة بأنها قدره الفرد وتمكنه من أداء الأعمال المطلوبة، وتحقيق الأهداف المرجوة الماندية

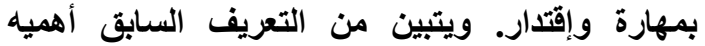

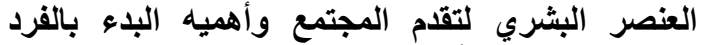

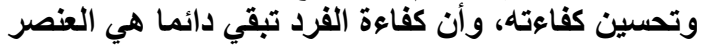

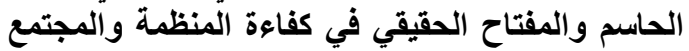

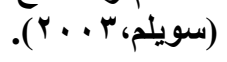

كما أشار "سويلم" أيضا إلى أن الكفاءة يمكن قياسها

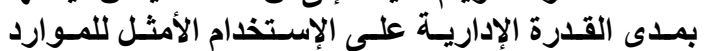
المتاحة سواء البشرية أو المادية (سويلم، ب + . r).

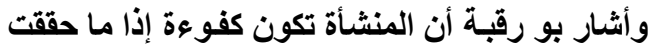

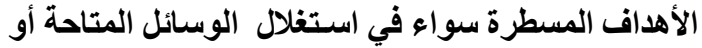

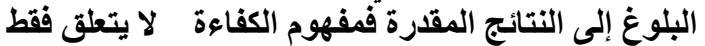

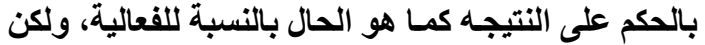
بكيفية الحصول على هذه النتيجة مع الأخذ بعين الإعتبـار

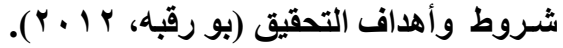

وفي هذا الصدد عرف Etzioni الكفاءة بأنها كمية الموارد المستخدمة لإنتاج مخرجات نظام اجتماعي معين

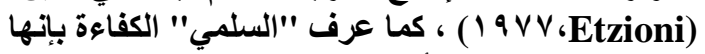
القدرة على تحقيق الأهداف المحددة بإستخدام المهام الموارد المتاحة أفضل إستغلال ممكن ـ (السلمي، 1919 1) . ومن خلال التعريفات السابقة التي يدور حولها مفهوم

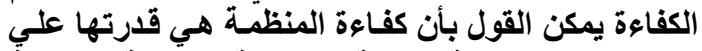

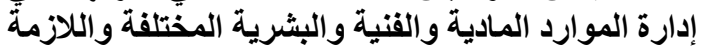
لأنثطتها والتي تتيح للعاملين بها التطبيق الجيد التئ للمعارف

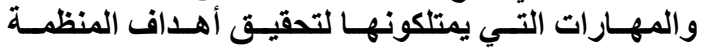

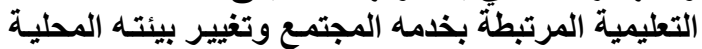
علي نحو أفضل.

كما يعرف "سويلم" الفعالية بانها القدرة على القيام

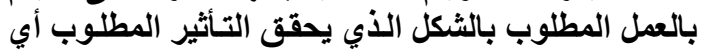

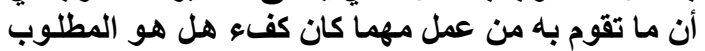

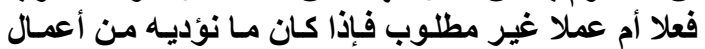
وأنثطة هو العمل المطلوب وهو النشاط النشاط المرغوب فمعني

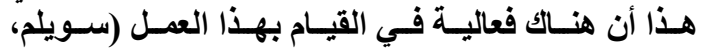
(r...r 
الجماعية) بواسطة عدد من الأدوات المناسبة تم إعدادها لهذا الغرض منها إستمارة إستبيان لعينة ممثلة من أولياء أمسـور التلاميــذ المســتهـفين، وإســتمارتين لمــديري العدرسـتين، عـلاوة علـى إسـتمارة إسـتبيان لكـل مسن المدرسين المشتركين بالمبادرة البالغ عددهم بـ إ مدرس

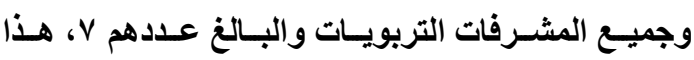
بالإضافة الي قائمة بعدد من الأسئلة الاسترشادية لأولياء

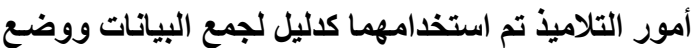
إطـار لإدارة المناقثـــات مـن خـلال المجموعـات البؤريـة المنفذة، حيث نقذت عدد ب حلقهه نقاثـية تم اختيـارهم بطريقة عمدية بحيث يكون لكل ولي أمر طفلان بالمبادرة وقد كان جميع أولياء الأمور من السيدات بواقع بات السيدة

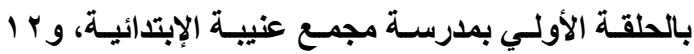

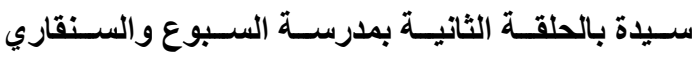

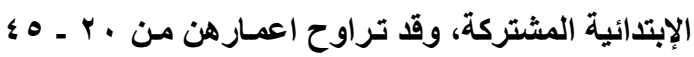

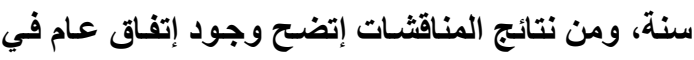
الرأي بين أولياء أمور التلاميذ بـالمجموعتين فيمـا يتعلق بالموضوعات المطروحة للنقاش في الحلقات النقاشية، هذا بالإضافة الي ملاحظة ـr طفل من أطفال المدرستين، عـلاوة علـي مــا تـم مـن لقـاءات مـع مســولي المشـروع لتعرف علي اهداف المبادرة وكيف تم الاعداد لها . ثانيا: مجالات البحث وقد تمثلت مجالات البحث في ثُلاث مجالات هي: 1 - المجال الجغرافي أجري البحث في محافظة أسوان بمركز نصر المبر النوبـة حيث منظقة تنفيذ المبادرة بالمحافظة . بحان

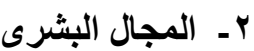
القسم المجال البشري لأريع فئات هما:

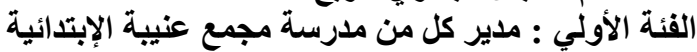
، ومدرسة اللسبوع والسنقاري الإبتأئية المشتركة.

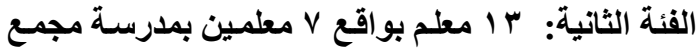

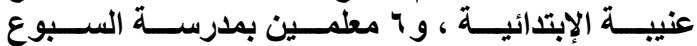
والسنقاري الإبتدائية المشتركة.

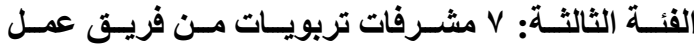
الجزويت والفرير.

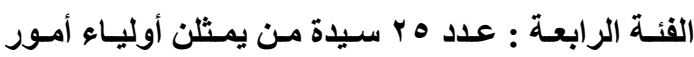

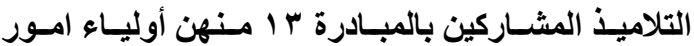

إلى المانحين والمجتمع الذى تعمل فيه، وذلك بهذف كسب المزيد من الفرص لتمويل مشرو عاتها وتقديم خدماتها

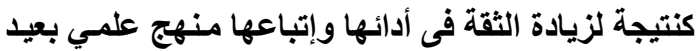
عن العثوائية. وهناك مؤسسات تطوعية رائدة فى المجتمع المصري يمتـ عمرهـا لأكثر مـن نصف قرن عمـل خيري بحيث

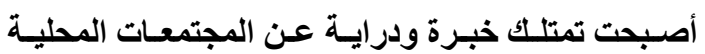
الفقيرة، بل وأصبح تحسين نوعية حياة الفــات الفقيرة أحـد أهدافها الأصيلة .ومـن أحــ هذه الجمعيـات جمعيـة الجزويـت والفريـر وهـي مـن المنظمــات غير الحكوميـة المصريةوقد تـم تأسيسـهـا وتسجيلها في عـام 1979 بهاف العمل في الأنثطة الإجتماعية والثقافية و التي سيتم

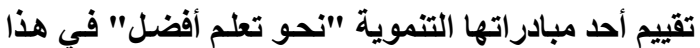

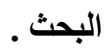
الطريقة البحثية :

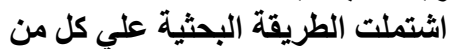

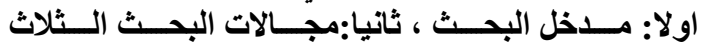

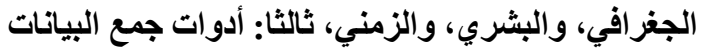

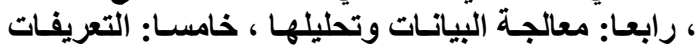
الاجرائية والقياس الرقمي.

$$
\text { أولا : مدخل البحث }
$$

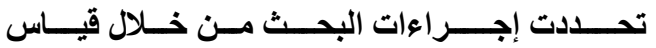

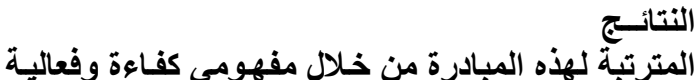

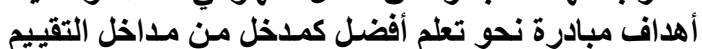

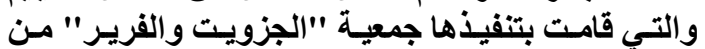
خلال مشروع تنمية مهـارات أطراف العمليـة التعليمية

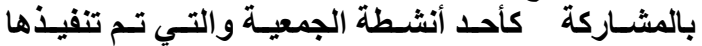

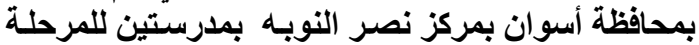

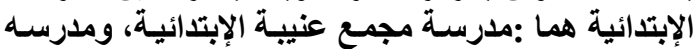
السبوع والسنقاري الإبتدائية حيث إستهدفت تلكت المبادرة

تمكين عدد r وحدة تلدريب من القيام بلرورها في مئي

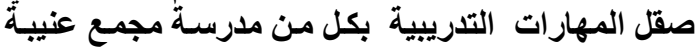

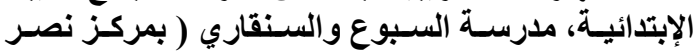

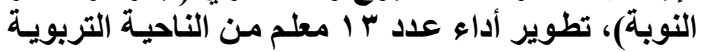

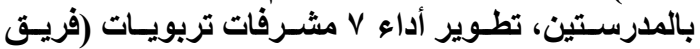

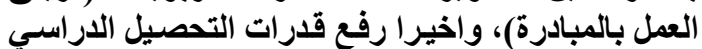
لعدد . . ا تلميذ من ضعاف المستوى الاراسي.

واعتمد البحث علي مجموعة من البيانـات الميدانية

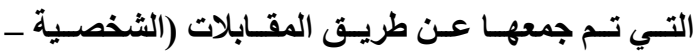


تم تحليل البيانات، بالاسلوب الوصفي الذي يعتمد الئو

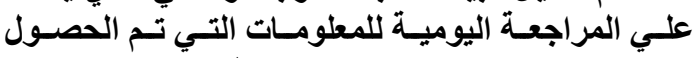

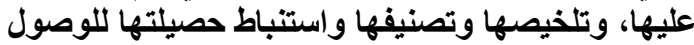

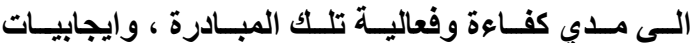

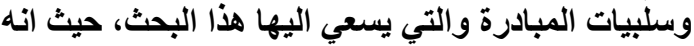

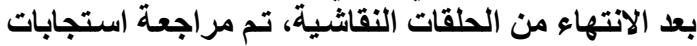

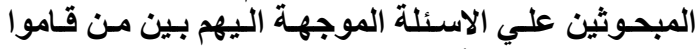

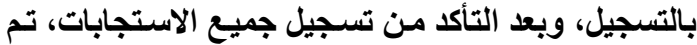

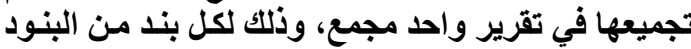

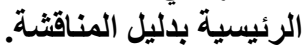

خامساً: التعريفات الإجرائية والقياس الرقمي :

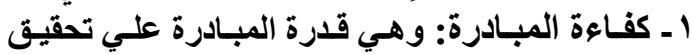

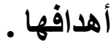

وقد تم تحليد درجة كفاءة المبادرة من خلال أربع

مؤشرات تعكس مدي تحقيق المبادرة لأهدافها وهي:

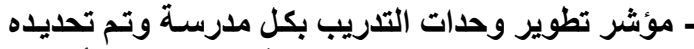

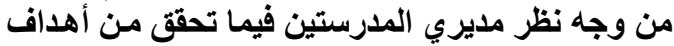

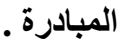

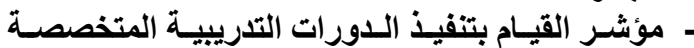

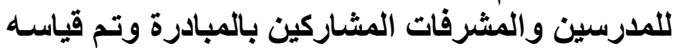
عن طريق المتوسط المرجح لنسبة حضور هم للدورات التدريبية.

- مؤشر درجة كفاية المدخلات التدريبية إستخدم في ذلك

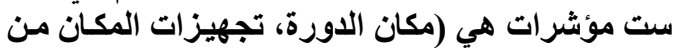

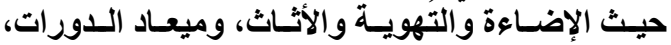

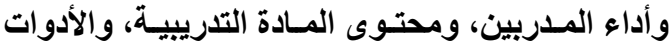

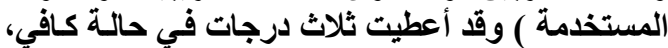

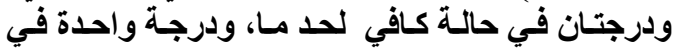

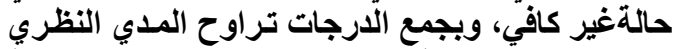

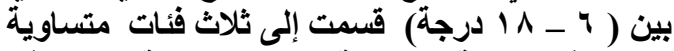

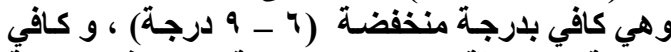

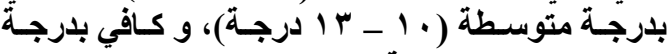

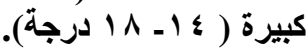

2- فعالية المبادرة: هي تعديد درجة نجاح المبادرة من خلال أراء المستفيدين منها هيا

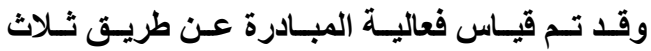

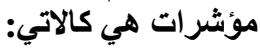

- مؤشر درجة تطبيق المدرسين والمشرفات للمحتوى

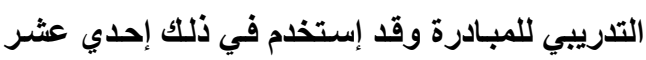

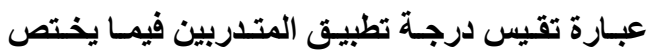

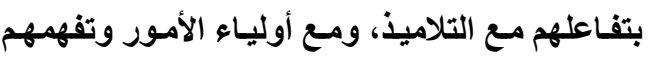

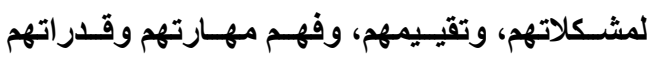

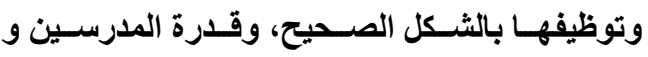

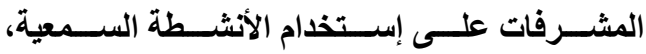
و الحركية، واللغوية، لضمان وصول المعلومة، ومدي
التلاميـذ بمدرسـة مجمـع عنيبـة الابتدائيسة، و با ا مـنهن

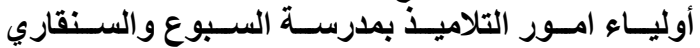
الابتدائية المشتركة.

الفئـة الخامسـة: مجموعـة مسن أطفـال المبـادرة والبـالغ عددهم · ب تلميذ.

r-المجال الزمني: جمت بيانات البحث خلال شهر يوليو

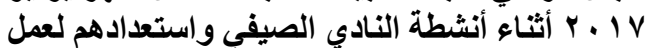
حفل ختامي لعرض نتائج ألمبادرة.

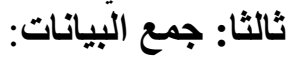

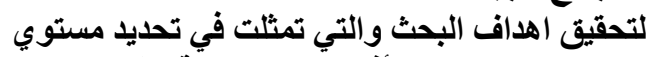

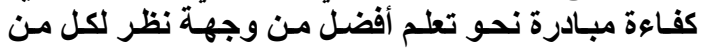

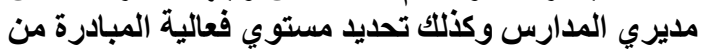

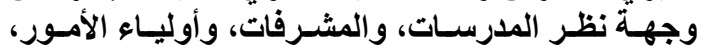
و التلاميذ، تعددت أدوات جمع البياتات كما يلي: والئياء

تـم اسـتخدام Y مـن المقـابلات المتعمقـة مـع مـديري

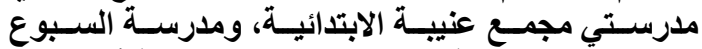

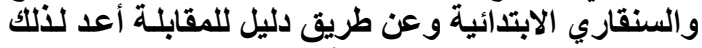
وقد إشتمل علي مدي تحقيق أهداف المبادرة في في تمكين وحدتي التدريب بالمدرستين.

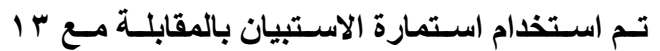

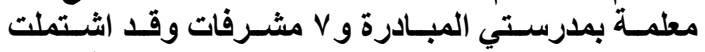

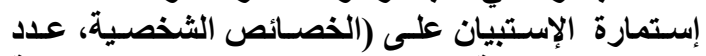

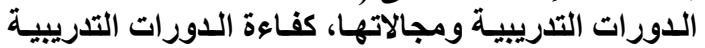

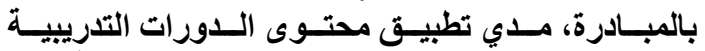

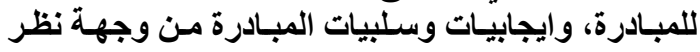
(المستفيدين).

تم استخدام الحلقات النقاشية مع أولياء أمور التلاميذ

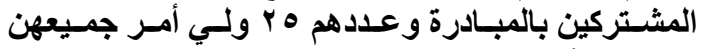

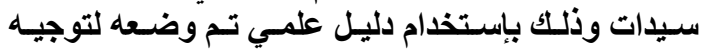
النقاش داخل المجموعات لمعرفة أرائهن في المبادرة من لئن

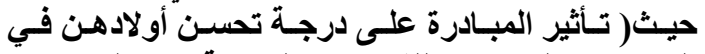

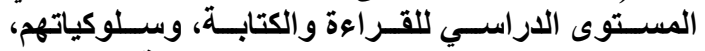

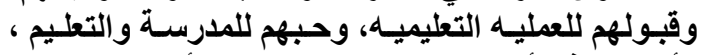
وأراءهن في أداء الددرسين بالمبادرة، وأخيرا إيجابيات وسلبيات المبادرة من وجهة نظرهن). - استخدام إستمارة إستبيان خاصة لكل سيدة من أولياء

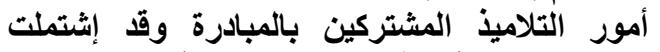

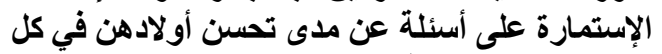

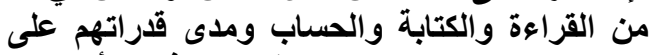

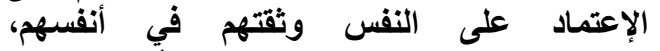

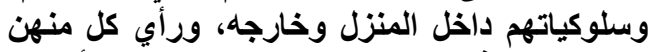

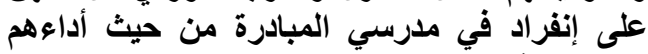
وقاراتهم في حل المشاكل. - استخدام اسلوب في الملاحظة وذلكك أثناء وجود الأطفال في احد الفصول المسائية بالمدرستين. رابعاً: معالجة البيانات وتحليلها: 
التدريبية، لذا كان من الضروري سؤال المبحوثين عن وجهات نظر هم في الاتي:

$$
\text { 1- تطوير وحدات التدريب: }
$$

من وجهة نظر مديري المدرستين وللتعرف علي مدي التئي

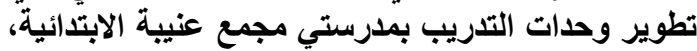

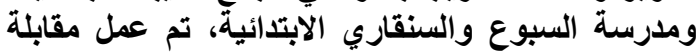

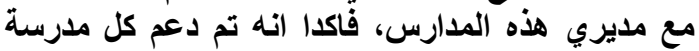

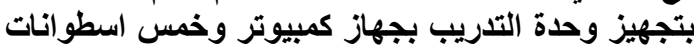

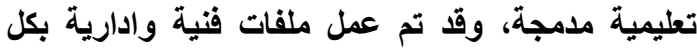

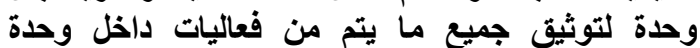

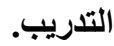

كما تم تاهيل القائمين والمسئولين عن هذه الوحدات

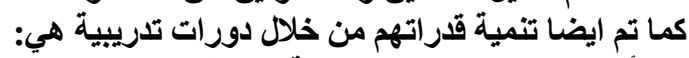
- - مأدوار وحدات التدريب وكيفية تنثيطها. - ـ دورة تدريب المدربين ( TOT) لمسئولي التدريب

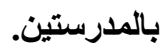

وقد أفاد مديري المدرستين بان مبادرة نحو تعلم

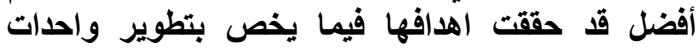

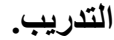

2- الدورات التدريبية الخاصة بالمدرسين: وللتعرف علي اذا ما كاتت مبادرة تعلم أفضل قد بلدابل حققت اهدافها فيما يخص بعقد خمس دورات للمدرسين

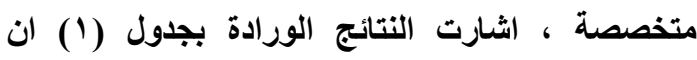
المبادرة قد قامت بعمل ه دورات تدريبية للمدرسات المشاركات في هذه المبادرة. وبالنظر الي بيانات الجدول السابق يتضح إرتفاع نسبة حضور المدرسات لهذه الدورات، حيث بلغت نسبة حضور دورتي التعلم النشط ، ومهارة وضع الاسئلة ج . . .

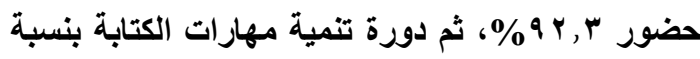

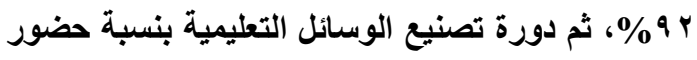
\%VV

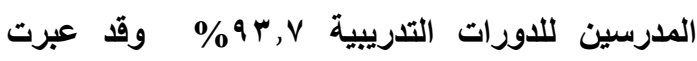
المبحوثات من المدرسات عن رضاهن وأقرن بأنهن يريدن مزيدا من الدورات من اجل استفادتهن شخصيا وكذلك تنمية قدراتهن على التعامل مع التلاميذ. 3- الدورات التدريبية الخاصة بالمشرفات

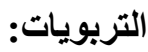

إضفاء روح من النشاط داخل الفصل، وزيادة قرتهم

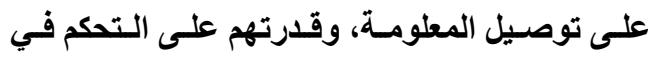
الفصل ـ وقد أعطي المتدرب ثلاث درجـات في حالة التطبيق بدرجة كبيرة، ودرجتان في حالة التطبيق بلرجـة متوسطة، ودرجـة واحدة في حالـة التطبيق وديق برجة ضعيفة، وبجمع درجات المتدرب تراوح المدي النظري بين (1 - ب ب درجة) قسمت إلى ثلاث فئات

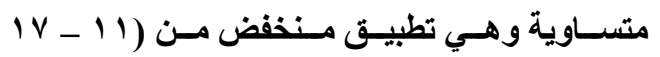

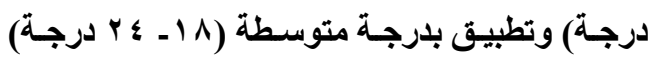

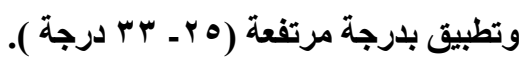

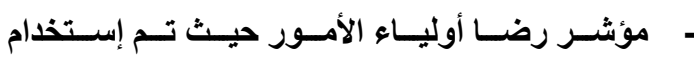
هاعبارة تعكس مدى تحسن أولادهن في كل من القراعة والكتابـة، والحسـاب، وقدرتهم على الإعتمـاد

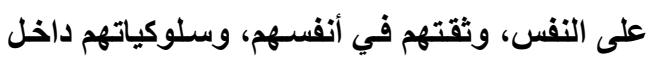

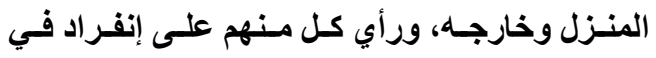

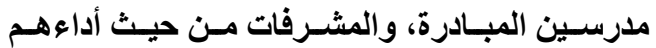
وقدرتهم على حل المشاكل، وقد أعطيت ثلاث درجـات

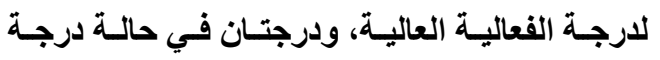
المتوسطة، ودرجة واحدة في حالة الفعالية الضعيفة،

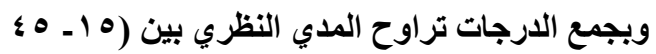

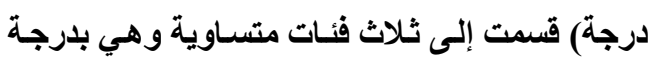

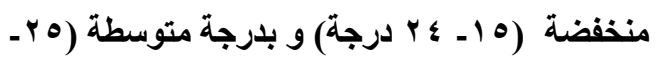

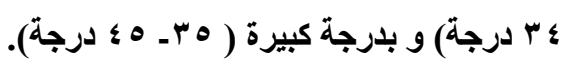

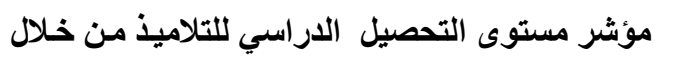

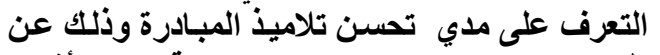

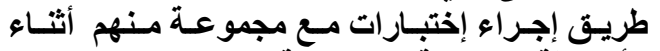

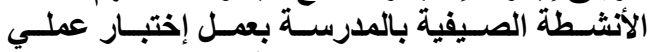

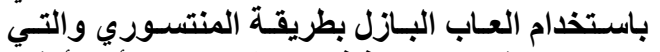
تعتمد على قدرة التلميذ في ربط الحروفي المرف أو الأرقام بالصور وتكوين الكلمات من الحروف.

تم عرضها كما هو مبين بالثكل رقم (1) تائج البحث: ترضه

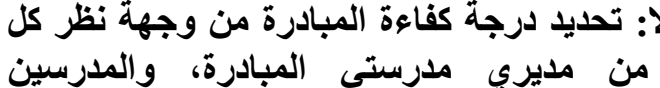
المشتركين في المبادرة:

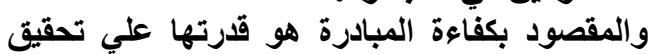

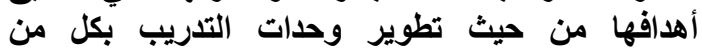

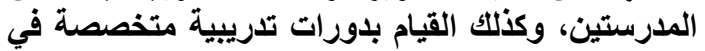
مجال التعلم النشطو واستراتيجياته، وأيضا كفاءة المدخلات 
المبادرة قد قامت بتنفيذ ه دورات تدريبية متخصصة في

ولمعرفة مـا اذا كانت مبادرة نحو تعلم افضل قد حققت

مجال استراتيجيات التعلم النشط.

اهدافها فيما يخص بعقد خمس دورات تدريبية للمشرفات

( فريق عمل المبادرة)، اتضح من نتائج جدول (r) ان
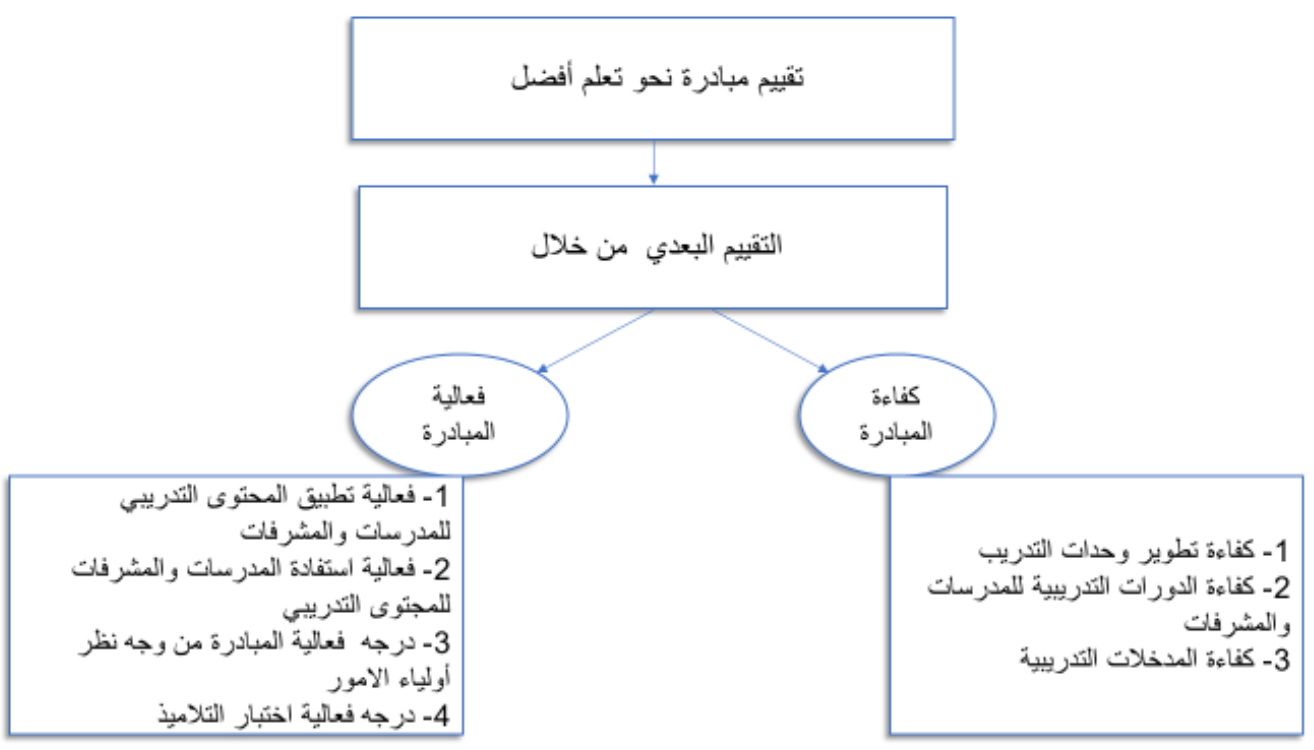

شكل (1 ): مقترح لتقيم مبادرة نحو تعلم أفضل

جدول ( 1): مجالات الدورات التي اطلقتها مبادرة نحو تعلم افضل ونسب حضور ها من وجهة نظر المدرسات

\begin{tabular}{|c|c|c|}
\hline نسبة الحضور\%\% & عدد الحضور(ن= r I I) & الدورات \\
\hline$\% 1 \ldots$ & ir & التعلم النشط \\
\hline$\% q r, r$ & ir & التعامل مع بيئة التلاميذ \\
\hline$\% \vee V$ & 1. & تصنيع الوسائل التعليمية \\
\hline$\% 1 \ldots$ & ir & مهارة وضع الاسئلة \\
\hline$\% 9 r$ & ir & تنمية مهارات الكتابة \\
\hline
\end{tabular}

جدول (ץ): مجالات الدورات التي اطلقتها مبادرة نحو تعلم افضل من وجهة نظر المشرفات

\begin{tabular}{|c|c|c|}
\hline$\%$ & عدد الحاضرين & مجالات الدورات \\
\hline $1 \ldots$ & V & تجربة دولة فلندا في التعليم \\
\hline $1 \ldots$ & $\mathrm{v}$ & دورة تصميم الالعاب التعليمية \\
\hline $1 \ldots$ & V & دورة قيم الحياة \\
\hline $1 \ldots$ & $v$ & دورة مهارات الاتصال والقيادة \\
\hline $1 \ldots$ & $\mathrm{V}$ & دورة الاصغاء الفعال \\
\hline
\end{tabular}

المبادرة) علي الحضور لتحقيق الإستفادة الكاملة من كل

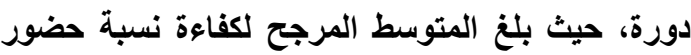

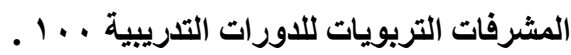

ويتضح من بيانات الجدول السابق أن هذه الدورات

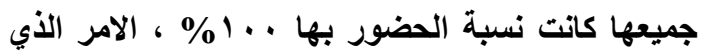
يشير الي التزام وحرص جميع المشرفات (فريق عمل ، الاهر 
مبادرة نحو تعلم افضل قد حققت أهدافها بثكل كبير في هذا المجال كما هو مبين في الثكل رقم (r). وويوضح الثكل رقم (2 ) المتوسط المرجح لكل من مؤشرات كفاءة المبادرة وهي ( تمكين وحدات التدريب التوليب

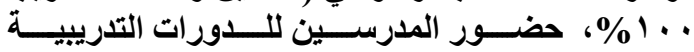

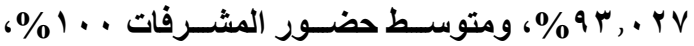

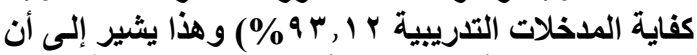

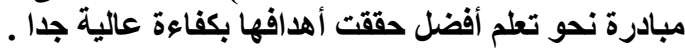

ثانيا: تحديد درجة فعالية مبادرة نحو تعلم أفضل من

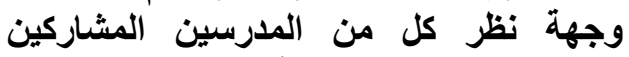
بالمبادرة، والمشرفات، وأولياء امور التلاميذ، والتلاميذ المستفدين بالمبادرة.

1- درجة تطبيق المدرسات والمشرفات للمحتوي الترريبي للاورات التّريبية:

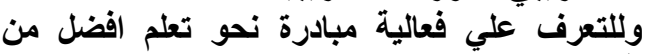

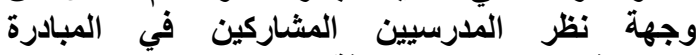

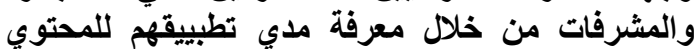

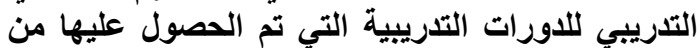

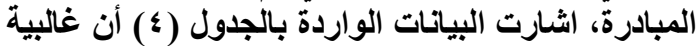

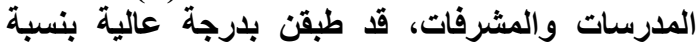

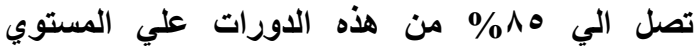

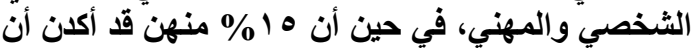

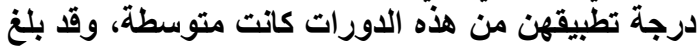

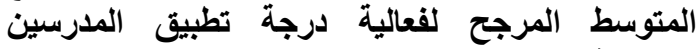

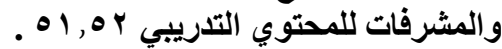

4- كفاءة المدخلات التدريبية: من المعروف ان المدخلات التدريبية لها اثر كبير

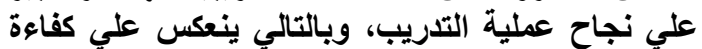
المبادرة، لان تجهيزات مكان التدريب من حيث الاضاضاءة والتهوية و الاثاث وكذلك كفاءة المدربين والثان المادة التدريبية

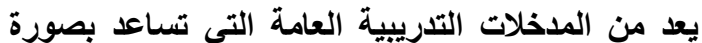
مباشرة في نجاح العملية التدريبية. ولمعرفة كفاءة المدخلات التدريبية في مبادرة نحو الفواه

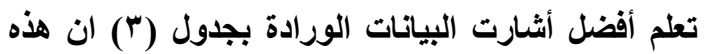
المدخلات كانت متو افرة بلرجة كبيرة في المبادرة بنسبة

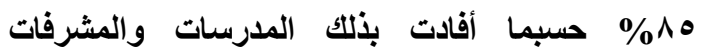

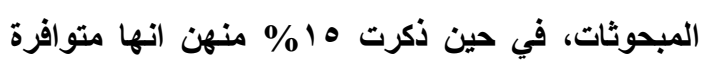
برجة متوسطة، وقد بلغ المتوسط المرجح لكفاءة

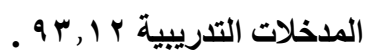

وقد أفادت المدرسات والمشرفات، أن المبادرة قد استخدمت أيضا بعض التجهيزات مثل الداتا شو والفيديو، وعرض الصور، والقصص، والالعاب، ولعب الادوار،

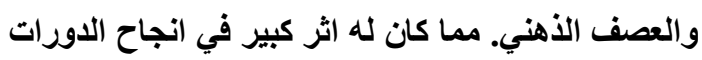
التدريبية. ولمعرفة مدي كفاءة مبادرة نحو تعلم أفضل من خلال تمكين وحدات التدريب وحضور المدرسات والمشرفات للاورات التدريبية، وكفاءة المذخلات التدريبية، يتضح ان

جدول (r): مدي كفاءة المدخلات التدريبية من وجهة نظر المدرسات والمشرفات المرات

\begin{tabular}{|c|c|c|}
\hline$\%$ & 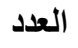 & الفئات \\
\hline- & - & منخفضة ( 7 - 9) درجة \\
\hline 10 & $r$ & متوسطة ( · - با ) درجة \\
\hline ^o & iv & كبيرة ( \& 1 - 1 ) درجة \\
\hline
\end{tabular}

\begin{tabular}{|lll|l|l|}
\hline & \\
\hline
\end{tabular}

شكل (r): مؤشرات كفاءة المبادرة 
جدول ( ؛ ) : درجة تطبيق المدرسين والمشرفات للمحتوى التّريبي للاورات التدريبية .

\begin{tabular}{|c|c|c|}
\hline$\%$ & العدد ن= · r & درجة التطبيق للمحتوي التدريبي \\
\hline - & صفر & منذفضة (I \\
\hline 10 & $r$ & متوسطة (^l - ؟ ) درجة \\
\hline ^० & IV & كبيزة (ه r - سr) درجة \\
\hline
\end{tabular}

التلاميذ، وإستطعن إكتثاف مهارات الأطفال المختلفة وذلك بنسبة . . 1 \% الكل منها.

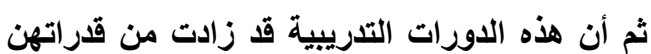

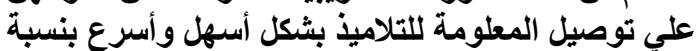

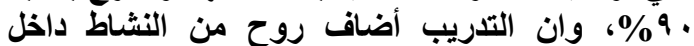

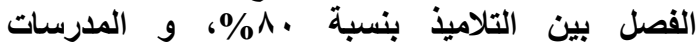
والمشرفات إستطعن عمل أنثطة سمعية وحركية ولغية ولغوية

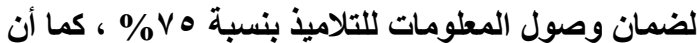

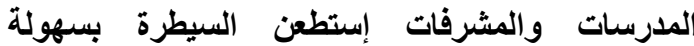

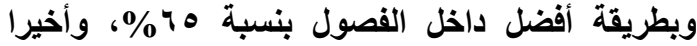

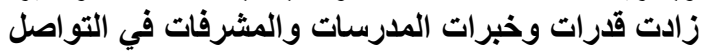

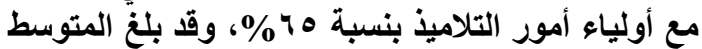

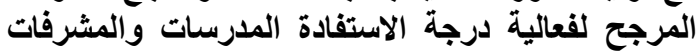

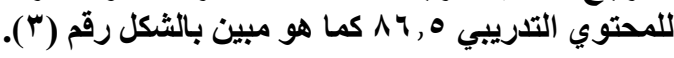

ويتضح من النتائج السابقة والخاصة بفعالية تطبيق

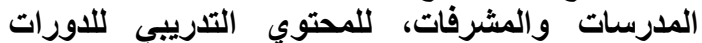

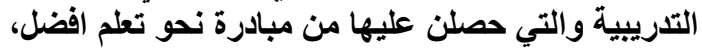

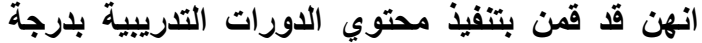

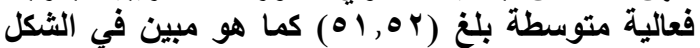

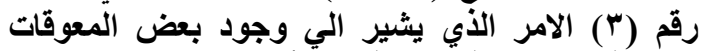

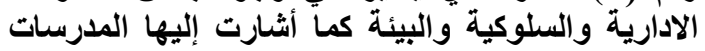

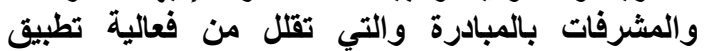
المحتوي التدريبي.

2- درجة الاستفادة من الدورات التدريبية اللاتي حصلت عليها المدرسات ومشرفات الاتورات المبادرة:

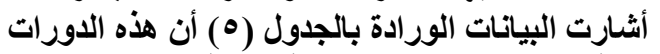

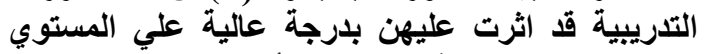

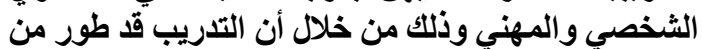
آدائهن داخل الفصل، وزيادة قدراتهن علي التواصل مع مع

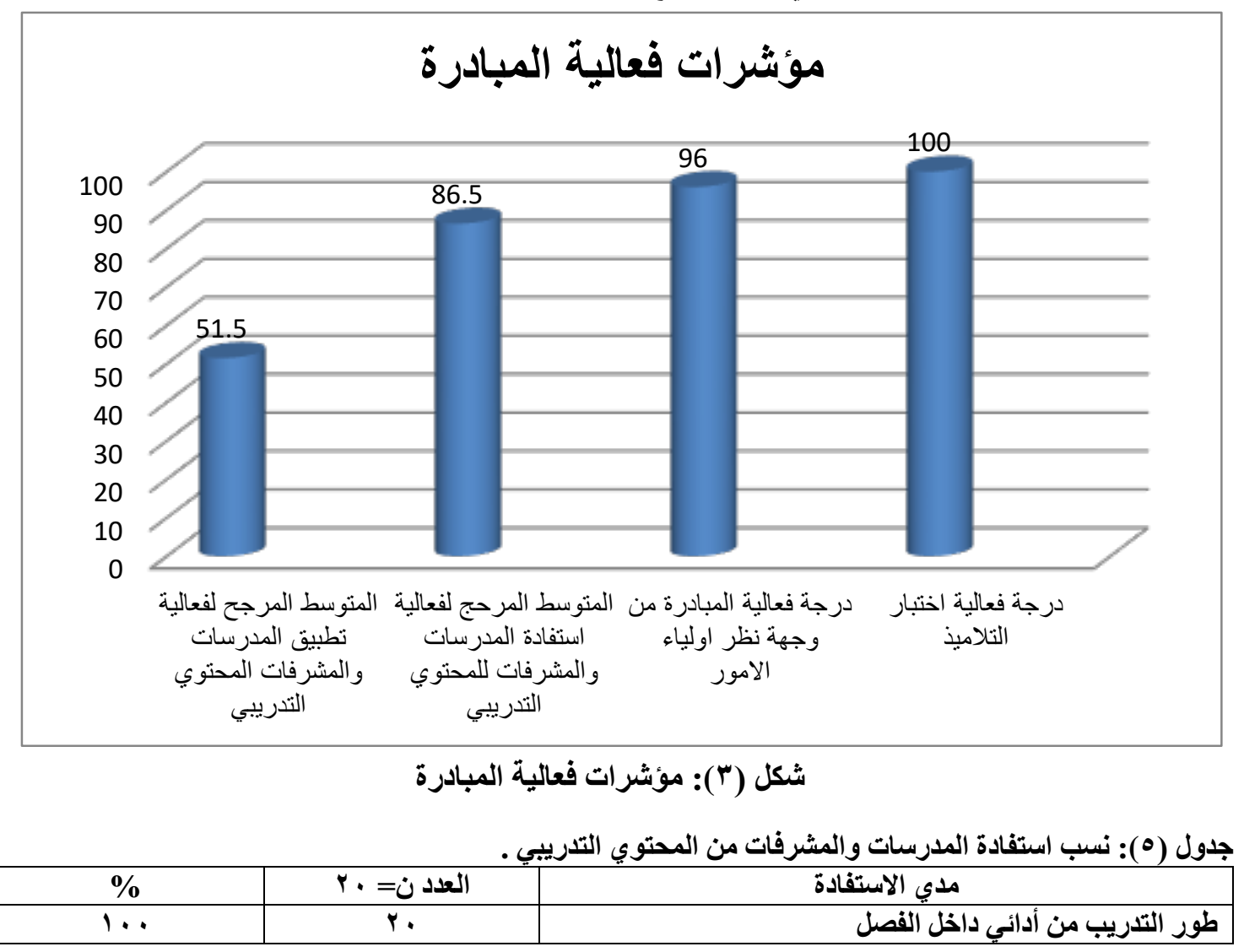




\begin{tabular}{|c|c|c|}
\hline $1 \ldots$ & r. & زادت قدراتي علي التواصل مع التلاميذ \\
\hline $1 \cdots$ & r. & اكتشاف مهارات الاطفال المختلفة \\
\hline 9. & 11 & زادت قدراتي علي توصيل المعلومات للتلاميذ بشكل اسهل \\
\hline & & 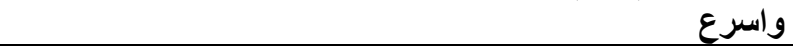 \\
\hline$\Lambda \cdot$ & 17 & التدريب أضاف روح من النشاط داخل الفصل \\
\hline V० & 10 & عمل انشطة سمعية وحركية ولغوية لضمان وصول المعلومة. \\
\hline 70 & ir & استطاعت المدرسة ان تسيطر علي التلاميذ بسهولة داخل الفصل \\
\hline 9. & ir & زادت خبرتي في التواصل مع اولياء الامور \\
\hline
\end{tabular}

باثتراكهم في هذه المبادرة، فقد أفادت السيدات( اولياء امور التلاميذ بمدرسة مجمع عينيبة الابتدائية) بالنسبة الاية الائية

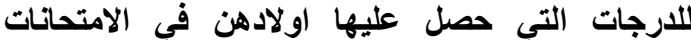

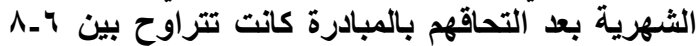

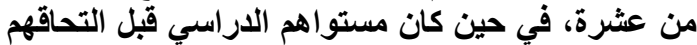

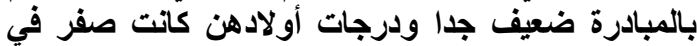
الإمتحانات الثهرية.

كما أفادت السيدات المبحوثات من ( أولياء أمور

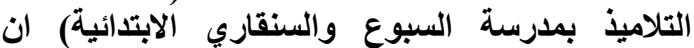

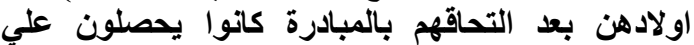

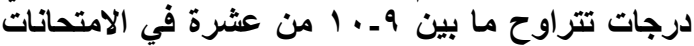

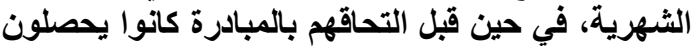

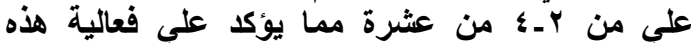

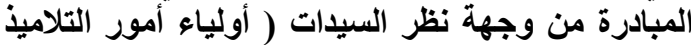

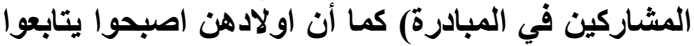

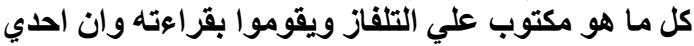

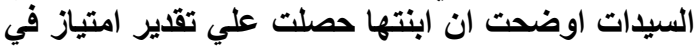
نهاية العام في الصف الثاني في جميع المواد الدئ الدراسية،

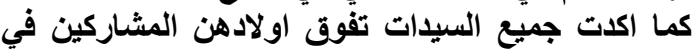

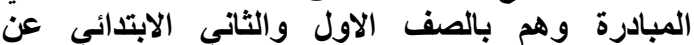
اخوانهن غير المشاركين في هذه المبادرة وهي والثم في الصفئ الخامس والسادس الابتدائي في القراءة والكتابئة

بـ تأثير مبادرة نحو تعلم أفضل علي سلوكيات

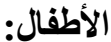

وقد تم سؤال السيدات المبحوثات من ( أولياء أمور

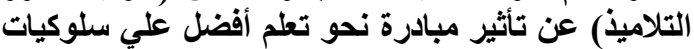

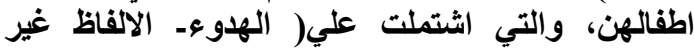

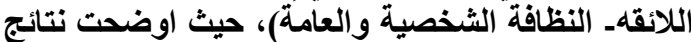

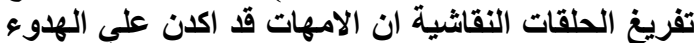
غير المسبوق علي أولادهن و هذا مان أكان أكدته إحدي الأمهات

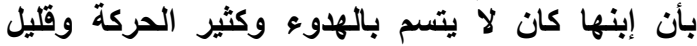
التركيز ولكنه بعد المبادرة قد تغير تماما.
وبالنظر الي النتائج السابقة والخاصة باستفادة

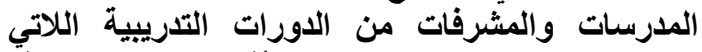
حصلن عليها من مبادرة نحو تعلم أفضل، يتضح التئ ان هذنه

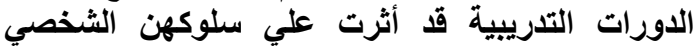

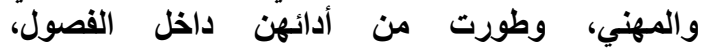
وباستخدامهن التدريبات العملية قد إستطعن إضافة إنية روح

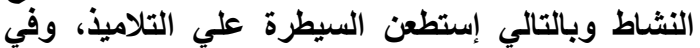

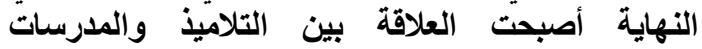

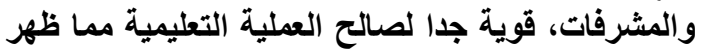

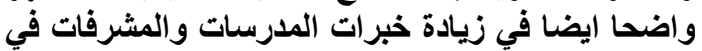

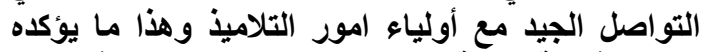

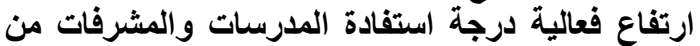

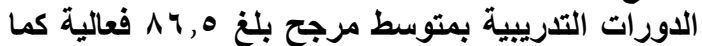
هو مبين في الشكل رقم (بات). 3- أولياء أمور التلاميذ:

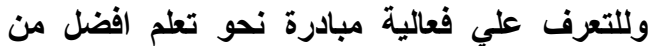

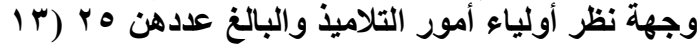

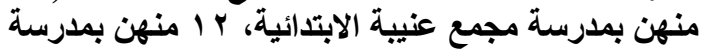
السبوع والسنقار الابتائية المشتركة).

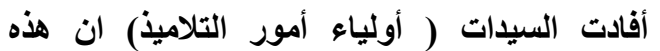

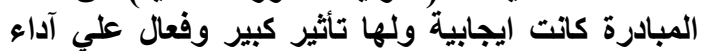

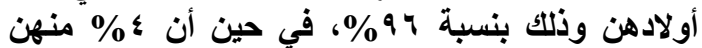

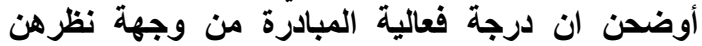

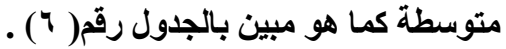

وللتعرف علي فعالية مبادرة نحو تعلم أفضل بشكل تفصيلي من وجهة نظر السيدات (أولياء امور التلاميذان

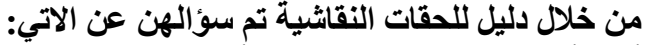
أ- ت تأثير المبادرة علي تحسن أولادهن في المستوي

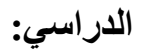

تم سؤال السيدات ( أولياء أمور التلاميذ) عن تأثير

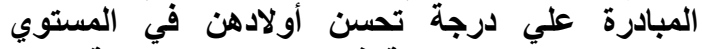

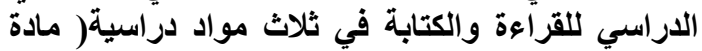

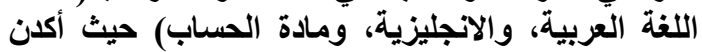
علي أن مستوي أولادهن قد تحسن بثكل ملحوظ

جدول (7): فعالية مبادرة نحو تعلم افضل من وجهة نظر أولياء أمور التلاميذ

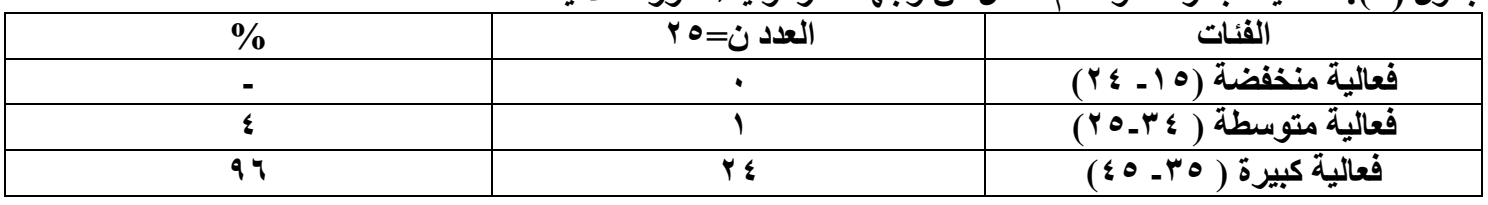


المعلومات للتلاميذ، كما انهن يتعاملن بحب وتشجيع دائم

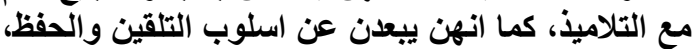

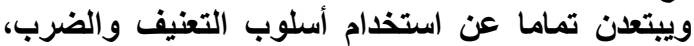
وذلك علي حد قول السيدات( أولياء أمور التلاميذ). حيث روت إحداهن ان المبادرة تعمل لمدة ؛ ايام في

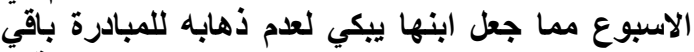

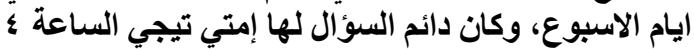
حتي يذهب للمبادرة.

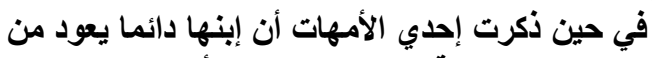

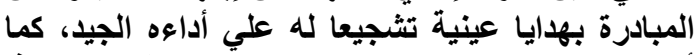

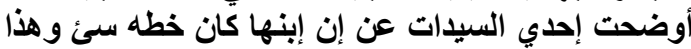

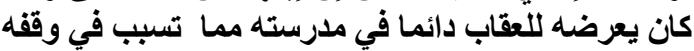

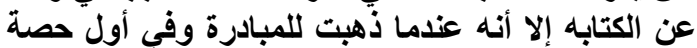

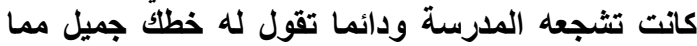
حفزته علي تحسن خطه بلرجه كبيرة.

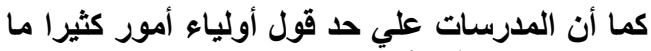

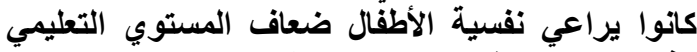

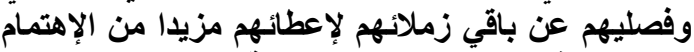
والوقت لرفع مستوياتهم لتكون قريبة من باقية باقي زملائهم.

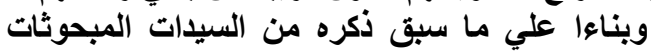

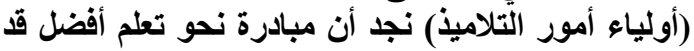

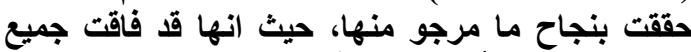
التوقعات وذللك للأسباب التالية:

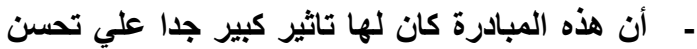

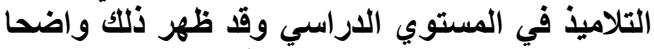

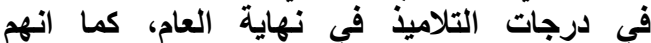

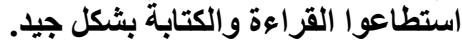

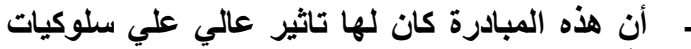

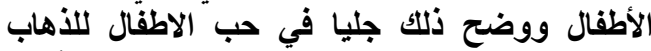

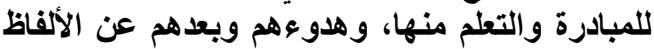

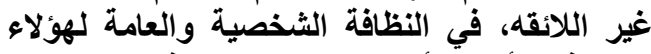

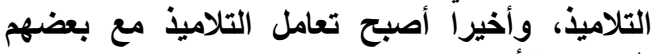

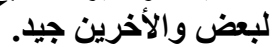

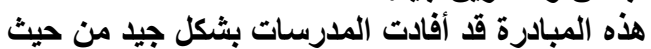

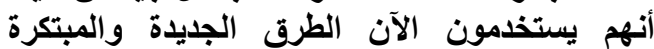

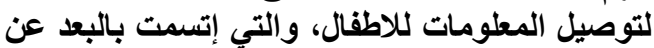

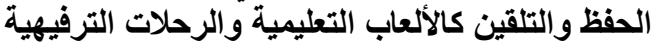
والثقافية، وتحفيز التلاميذ بالكهابيا العيدية والعية.

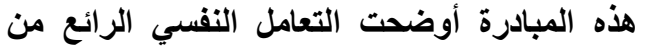

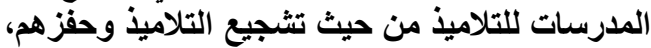
وفصل التلاميذ ضعاف المستوي التعليمي لتقويتهم ليصبحوا قربين جدا من اقرانهم في نفس المسئ المراحل الار اسبة. -

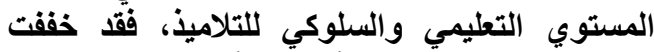

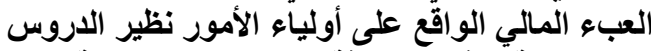

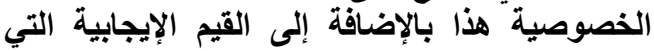

جمعت وحسبت من خلال استمارة استبيان.

بينما اشارت إحدي السيدات ايضا ان ابنها كان كثير الفان

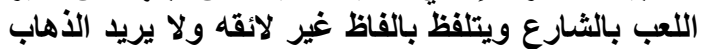

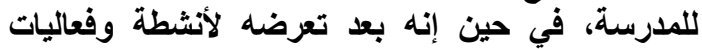

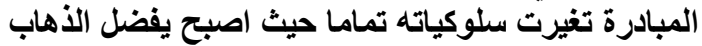

لفصول المبادرة عن اللعب في الشارع.

كما اكدت جميع السيدات من المبحوثات ( أولياء أمور

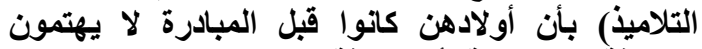

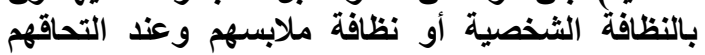

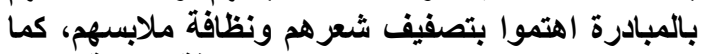

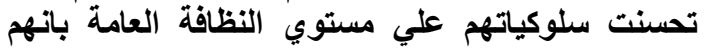
تعلموا إلقاء القمامة في سلة المهياتهلات.

كما أكدت إحدي السيدات قيام ابنها بتعليم جميع

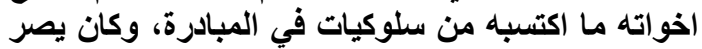

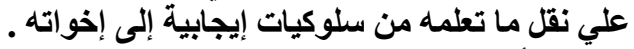

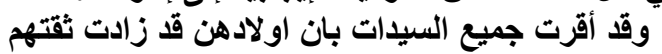

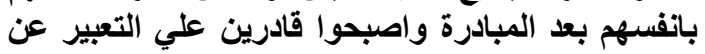

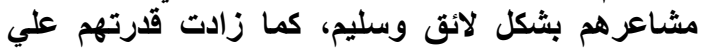

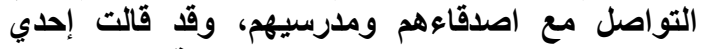

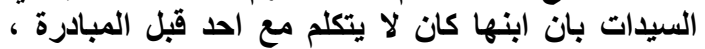

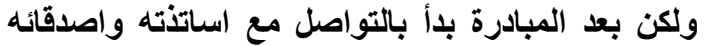

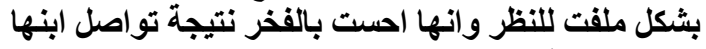
بهذه الطريقة الجيدة وقالت ( قلبي انشرح بـابت بالفيني).

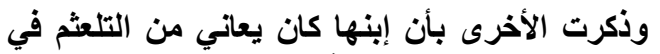

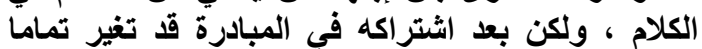
و أصبح يتحلث بطرن بعريقة طبيعية.

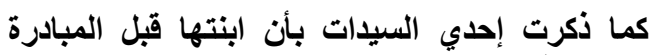

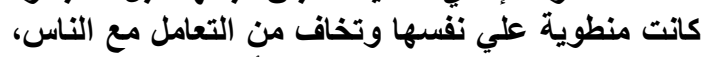

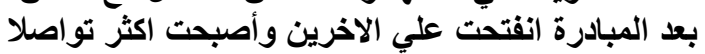
وثقة بنفسها.

كما أفادت إحدي السيدات بان ابنها قبل المبادرة كان

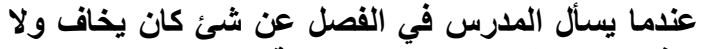

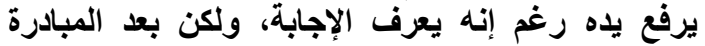
أصبح أول من يرفع يده للاجابة. ج- آراء أولياء أمور التلاميذ في أداء الدابة المدرسات

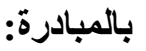

وللتعرف علي آراء أولياء أمور التلاميذ في أداء أمواء

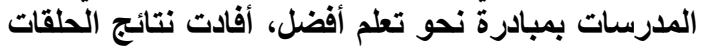

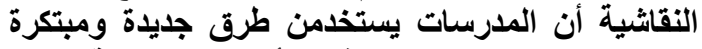

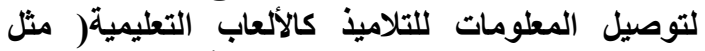

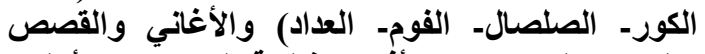

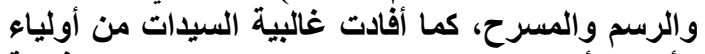

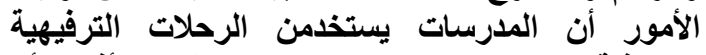
والثقافية للبعد عن اسلوب التلقين والحفظ، كما أفدن بأن التردئ

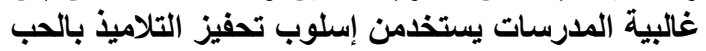

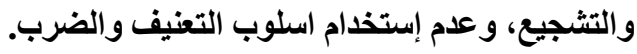

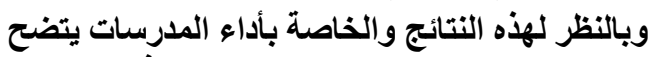
إنهن يستخدمن اسلوب تربوي حديث في توصيل 
الدراسي للتلاميذ واندماج التلاميذ في العملية التعليمية وذلك بنسبة r, ץ 9\% لكل منها علي الترتيب.

إكتساب المدرسين القرة على إكتثاف مواهب

الأطفال بنسبة 9, .9\% تنمية مهارات الإتصال بين

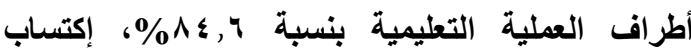

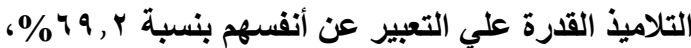

قدرة التلاميذ علي تعديل السلوكيات الخاطئة، واستخدام

المبادرة إستراتيجيات التدريس الفعال، بنسبة \,117\% لكل منهما علي الترتيب، واخيرا تغيير نوعية الحياة لكل من المدرسين وأولياء الأمور.

وبالنظر الي إيجابيات مبادرة نحو تعلم أفضل من وجهة نظر أولياء الأمور، نجد أنها تتمثل في إرتفاع مستوي التحصيل الدراسي للتلاميذ بنسبة ...1\%، ثم إكتساب التلاميذ القدرة علي تعديل السلوكيات الخاطئة بنسبة •^\%، ثم قدرة التلاميذ عن التعبير عن أنفسهم بنسبة . ٪\%، ثم اندماج التلاميذ في العملية التعليمية

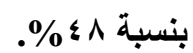

2- سلبيات مبادرة نحو تعلم أفضل:

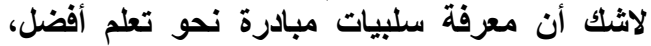

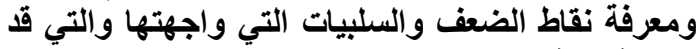
تؤثر في هذه المبادرة بثكل سلبي، سيفيد القائمون علي والتي

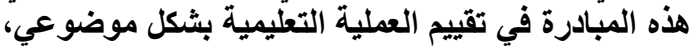

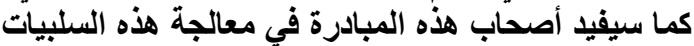
عند القيامم بمثل هذه المبادرات مستقبلا.

وللتعرف علي هذه السلبيات أفادت البيانات الورادة بجدول (^) ان هذّه السلبيات من وجهة نظر المدات المدرسين،

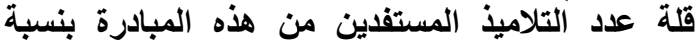
، \% 9,9

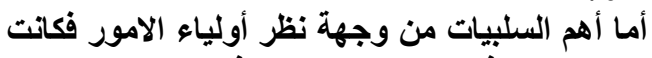

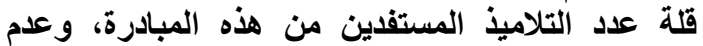

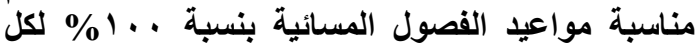
منها، تلي ذلك عدم وجود إضاءة وتهوية كافية داخل

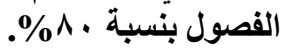

تعلمها هؤلاء التلاميذ والتي أثرت بثكل كبير علي تعاملهم مع أسر هم ومجتمعاتهه.

4- تطبيق اختبار علي التلاميذ المستهدفين من المبادرة: - المبن

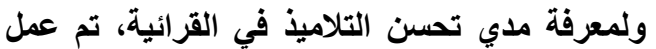

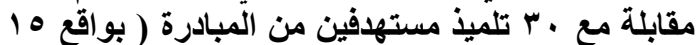
تلميذ بكل مدرسة من مدرستي مجمع عنئية منية الابتدائية،

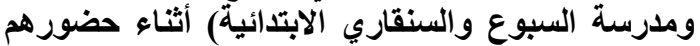
فصول القرائية ومن خلال الأنشطة الصيفية الائية بالمدرسة، وللتعرف علي التحسن في مستوي التلاميذ، تم إستخدام

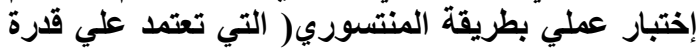
التلاميذ علي ربط الحروف او الارقام بالصور وتكوين الكلمات من ألحروف).

وقد تم تطبيق هذا الاختبار بتقسيم التلاميذ بالفصل

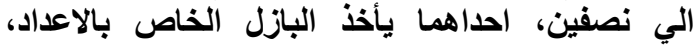
والاخر ياخذ الصور. وعلي التلميذ ان يبحث عن الثُكل

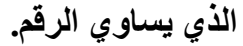

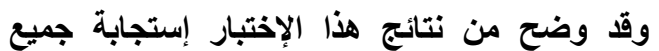

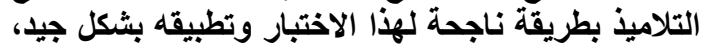

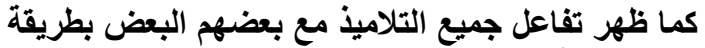

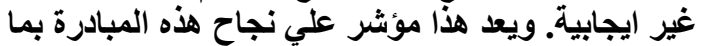
يشير إلى فعاليتها. ويتضح من خلال استعراض نتائج البحث الخاصة

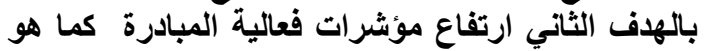
مبين بالثكل رقم ("آ).

ثالثا: التعرف علي ايجابيات وسلبيات مبادرة نحو تعلم أفضل من وجهة نظر كل من المدرسين

$$
\text { و وأولياء الامور: }
$$

ولتطوير أسلوب العمل بمبادرة نحو تعلم افضل، كان

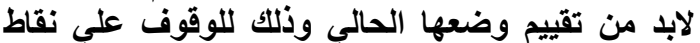

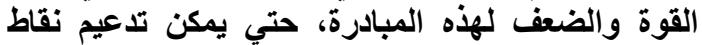
القوة، ومواجهة نقاط الضعف لتعديلها. 1- إيجابيات مبادرة نحو تعلم أفضل: وللتعرف علي هذه الإيجابيات، والتي تتمثل في الموارد المتو افرة لدي هذه المبادرة، وكذلك القدرات التي يمكن استغلالها بهذه المبادرة، اظهرت النتائج الورادة

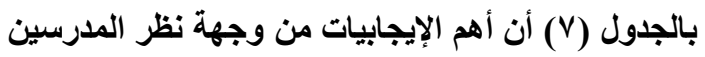

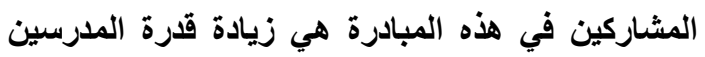
علي توصيل المعلومة، وارتفاع مستوي التحصيل

جدول (V): إيجابيات مبادرة نحو تعلم افضل من وجهة نظر المدرسون وأولياء الامور.

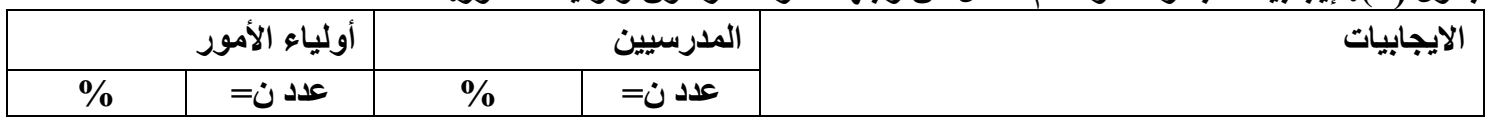


An evaluation of the social initiative "Twards Better learning" in Aswan

\begin{tabular}{|c|c|c|c|c|}
\hline & ro & & Ir & \\
\hline$\% \leq$ & 1. & $\% \wedge \varepsilon, 7$ & 11 & تنمية مهارات الإتصال \\
\hline$\%$ rr & $\Lambda$ & $\% q r, r$ & ir & زيادة القدرة على توصيل المعلومة \\
\hline$\% r$ & $\bullet$ & $\% \vee 7, q$ & 1. & اكتثاف مواهب الأطفال \\
\hline$\%$ & 10 & $\% 99, r$ & 9 & قرة التلاميذ على التعبير عن أنفسهم \\
\hline$\% \wedge$ & r. & $\%$ & $\Lambda$ & تعديل السلوكيات الخاطئة \\
\hline$\% 1 \ldots$ & ro & $\% q r, r$ & ir & ارتفاع مستوى التحصيل الدراسي \\
\hline$\% \leqslant \wedge$ & Ir & $\% q r, r$ & Ir & اندماج الأطفال في العملية التعليمية \\
\hline- & - & $\% 71,0$ & $\Lambda$ & استخدام أساليب تدريبية متطورة \\
\hline- & - & $\% \leq 7,1$ & 7 & تغيير نوعية الحياة للمشاركين بالمبادرة \\
\hline \multicolumn{5}{|c|}{ جذول (^): سلبيات مبادرة نحو تعلم أفضل من وجهة نظر كل من المدرسون واولياء الامور } \\
\hline \multicolumn{2}{|c|}{ اولياء الامور } & \multicolumn{2}{|c|}{ 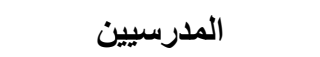 } & \multirow[t]{2}{*}{ 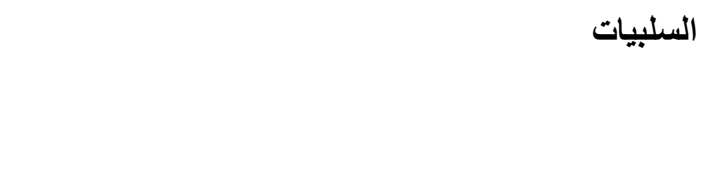 } \\
\hline$\%$ & عدد ن & $\%$ & عدد ن & \\
\hline$\% \wedge$ & $r \cdot$ & - & - & عدم وجود إضاعة وتهوية كافية داخل الفصول بالمدارس. \\
\hline$\% 1 \ldots$ & ro & $\% 9 \cdot, 9$ & 1. & قلة عدد المستفيدين من التلاميذ . \\
\hline$\% 1 \ldots$ & ro & - & - & عدم مناسبة مواعيد الفصول المسائية \\
\hline
\end{tabular}

الإهتمــام بالعمـل على تغييـر المكـون المعرفـي والسـلوكي للمدرسـين ومحاولـة اكسـابهم مهـارات بطرق إبداعية وابتكارية بلورة مفهوم الشر اكة دعم وتوسيع مفهوم الشراكة بين القطاع الحكومى والقطاع الخـاص والمنظمـات غير الحكوميـة فـى تحمـل أعبـاء العمليـة التعليميـة باعتبار هـا قضية أمسن قومى سـواء أكسان ذلك في تدبيز الموارد المادية أو البشرية. 4- عداد خريطة مستقبلية واضحة المعالم يتحدد من خلالها الإدوار المنوطة بالجمعيات الأهلية فى مجال التعليم حتى يتسنى لها المشاركة الجـادة فى تطوير التعليم بنـاء علاقـات قويـة ومترابطـة بـين أفراد المجتمـع $-5$ المحلي ويناء قدراته من خلال مبادرات تهدف الىى تحسين نوعية الحياة .
ومن النتائج السابقة والخاصة بسلبيات مبادرة نحو

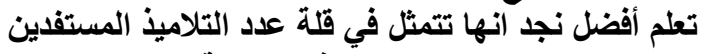

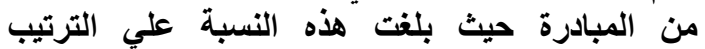

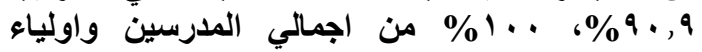
مما يستلزم مراعاة ذلك في المبادرات القادمة حتي

$$
\text { تؤتي ثمار ها. }
$$

مسن النتـائج السـابقة يمكن التقدم بعض التوصسيات،

$$
\text { وذلك على النحو التالي : }
$$

1- المنظمـات التعليميـة لا تقـوم بـدورها علـى النحـو

الأكمـل ولــلك لابــ مـن التعساون بـين المنظمـات

الرســية وغيـر الرســية (مؤسســات المجتمــع

المدني، قطـاع رجـال الأعمـال) لرفع كفـاءة العملية 


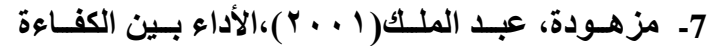

والفعالية مفهوم وتقييم، مجلة العلوم الإنسـانية، كليه

الحقوق، جامعة محمد خيضر بسكرة .

8- عبد المجيد، محسن بهجت محمد، محددات أداء بعض ه

المنظمــــات الريفيــــة فــــي مجتمعــــات الأراضــــي

الجديـدة، (999 9 19) رسـالة دكتـور اه، قسـم الاجتمــاع

الريفي والإرشاد الزراعي، كلية الزراعة، جامعة عين

شمس.

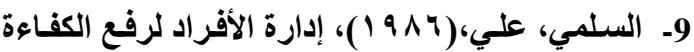

الإنتاجية، دار المعارف بمصر، القاهرة .

$$
\text { المراجع الأجنبية : }
$$

10- Beadeian, Arthur, Organization Theory, Dryden Press, (1980).

11- Becker and, Newhauser, the Efficient organization, New York, (1975).

12- Etzioni, amitai,Comparative Analysis of Complex Organization, frec press, Charles Mulford, (1977).

13- Deen.J, Champion. "Sociology of Organization, MC Graw-Hiu, Book Company, New York, 1975.
اولا: المراجع العربية:

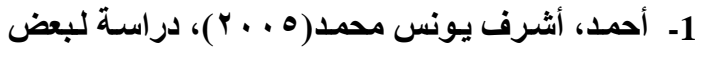

العوامل المؤثرة علي فعاليـة جمعيات تنمية المجتمع

المحلي في الريف المصري، رسـالة دكتور اه، قسم

المجتمع الريفي والإرشــاد الزراعي، كلية الزراعة،

جامعة عين شمس.

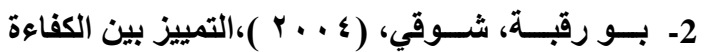

و الفعالية والأداء، كلية العلوم الاقتصادية وعلوم

التسيير جامعة فرحات عباس - سطيف الجزائر.

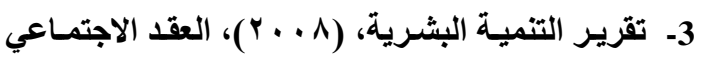

فـي مصـر دور المجتمـع المــنـي، معهـــ التخطسيط

القومي.

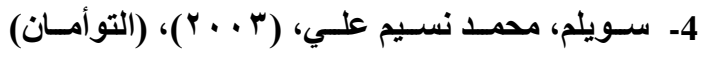

الكفاءة و الفاعلية، مصر للخدمات العلمية، القاهرة .

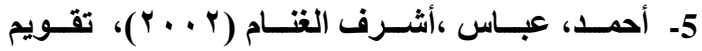

المشروعات الإجتماعية، مذكرات تمهيدي ماجستير،

قسم الإجتماع والعلوم الإنسانية، جامعة الإمارات .

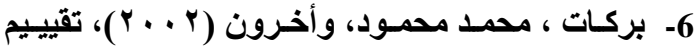

المشروعات الاجتماعية الريفية،جامعة عين شسم

كليه الزراعة، التعليم المفتوح . 


\title{
AN EVALUATION OF THE SOCIAL INITIATIVE "TWARDS BETTER LEARNING" IN ASWAN GOVERNORATE (case study)
}

\author{
Hanan M. Farag and Doaa M. Salih \\ Agriculture Extension and Rural Development Research Institute, Agriculture Research \\ Center, Giza, Egypt
}

\begin{abstract}
The study aimed to evaluating a social initiative "Towards Better education" implemented by one civil society in two school in Aswan governorate through determining the efficiency level of the mentioned societal initiative from the view of the directors and the teachers participated in and the effectiveness level of it from the view of the teachers and the student's parents and students themselves. In addition to the positives and negative aspects of initiative from the view of the teachers and student's parents to achieve the study objectives many data collection methods were used as interviews, questionnaires, group discussion, and observation.

The study included two categories, the first one included the two directors of the two schools, 13 teachers, and 7 supervisors. While the second composed of 25 student's parents from those who have two children in the initiative, so the students number amounted to $50 \%$ of the students targeted number.

The results of the study were as follows:

The efficiency and effectiveness level of the initiative were high from the view of all the different participants in this initiative. The positive aspects of this initiative were that teachers, students for achieved more capabilities for knowledge transfer, and the high level of students for achiving lesson and joining the education process with $92.3 \%$ respectively - As for the students, parents, the results showed that students with $100 \%$ achieve high rank in their studying regarding the negative aspects of the initiative were the limited number of the students who participated in it and unsutable times of the evening class rooms as mentioned by the teachers and the student's parents (90.9\%).
\end{abstract}

Key words: efficiency and effectiveness initiative.

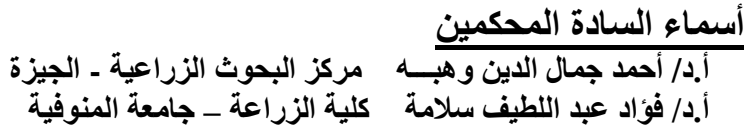

